\title{
Interrelações Entre Eventos ENOS (ENSO), a ZCIT (ITCZ) no Atlântico e a Chuva nas Bacias Hidrográficas do Ceará
}

\author{
Teresinha de Ma. Bezerra S. Xavier \\ Depto. de Hidráulica e Curso de Mestrado em Recursos Hídricos - Centro de Tecnologia - UFC - Academia Cearense de Ciências \\ Rua Oswaldo Cruz, 176/400 - Meireles - CEP60125-150 Fortaleza, CE - txavier@secrel.com.br
}

Airton Fontenele Sampaio Xavier

Univ. Fed. do Ceará - UFC - Univ. Estadual do Ceará - UECE - Curso de Mestrado em Computação Profissionalizante - UECE-CEFET

\author{
Maria Assunção Faus da Silva Dias e Pedro Leite da Silva Dias \\ Depto. de Ciências Atmosféricas - IAG (Inst. Astronômico e Geofísico) - USP
}

Recebido: 10/01 - revisão: 08/02 - aceito: 04/03

\begin{abstract}
RESUMO
Considera-se neste artigo uma avaliação das interrelações entre ocorrências de eventos ENOS = "El Niño-Oscilação Sul" (ENSO = "El Niño-Southern Oscillation") no Pacifico, posições médias da ZCIT = "Zona de Convergência Intertropical" (ITCZ = "Intertropical Convergence Zone") no Atlântico, com respeito à chuva acumulada nas principais bacias hidrográficas do Estado do Ceará durante a "quadra chuvosa", climatologicamente corresponde ao quadrimestre fevereiro-maio; bem como, também levando em conta a chuva mensal ao longo do primeiro semestre de cada ano, ou seja, de janeiro a junbo. São tratadas apenas 6 (seis) das 11 (onze) bacias usualmente definidas para o Ceará; contudo, cobrindo expressiva fração da superficie total do Estado e as áreas consideradas mais importantes sob os aspectos populacional e econômico. Os resultados revelam um papel significativo da migração da ZCIT para o sul da linha equatorial, isto é, para latitudes mais próximas ao território cearense, no sentido da instalação de chuvas sobre suas bacias, não só as situadas nas proximidades do litoral como, ainda, aquelas mais interioranas ou no extremo sul do Ceará. Ademais, ficou revelado nitidamente o papel das ocorrências de eventos ENOS no Pacífico, com relação à descida para o sul da ZCIT no Atlântico e, também, com as chuvas nas bacias. De fato, o trabalho fornece subsídios para a análise da vulnerabilidade climática dessas bacias hidrográficas. Por outro lado, relaciona-se com o Projeto "Tempo de Chuva", para previsão regionalizada da chuva no Estado do Ceará e nas suas bacias durante a "quadra chuvosa".
\end{abstract}

Palavras-chave: ZCIT no Atlântico; episódios ENOS (ENSO); chuvas nas bacias do Ceará

\section{INTRODUÇÃO}

A rede hidrográfica do Estado do Ceará consta de um total de 11 (onze) bacias, algumas delas sub-bacias de outras mais amplas. Considera-se, em particular, o caso da Bacia Metropolitana que compreende a Região Metropolitana de Fortaleza e, de fato, um conjunto de bacias de pequeno porte reunidas em vista da importância da região coberta, em termos populacionais como econômicos; porém, ainda, por comportar o Complexo Pacoti-Riachão-Gavião, sistema de reservatórios destinado ao abastecimento de Fortaleza e municípios vizinhos. Em um trabalho anterior, Xavier et al. (1999), tratou-se preliminarmente sobre o significado do posicionamento da ZCIT (Zona de Convergência Intertropical) e da sua migração ao sul do equador no primeiro semestre de cada ano, para a definição da "quadra chuvosa" sobre as principais bacias no Estado do Ceará. Por outro lado, em Xavier et al. (2000a), examinou-se a mesma questão no que concerne à chuva em regiões pluviometricamente homogêneas.
Aqui, os resultados se estendem, considerando-se não só as interrelações da chuva nas bacias e da ZCIT no Atlântico como, também, respeito às ocorrências de eventos ENOS - "El Niño-Oscilação Sul” no Pacífico. Numa primeira etapa levam-se em conta as relações de eventos do "ciclo" ENOS/ENSO ("El Niño" e "La Niña") relativamente à posição média da ZCIT e ainda com a chuva nas bacias, em fevereiro-maio. Em seguida, vai-se recapitular detalhadamente a relação entre a posição média da ZCIT, mês a mês, a partir de janeiro até junho, com a chuva acumulada sobre as bacias, conforme foi tratado anteriormente em Xavier et al., 1999, op. cit.

Note-se que a importância das águas oceânicas sobre o clima já havia sido mencionada por Von Humboldt, conforme passagem existente na sua obra Kosmos, 1843-1858. No que se refere à influência de eventos no Pacífico equatorial sobre as chuvas no Nordeste brasileiro e no Ceará é preciso mencionar o artigo de Caviedes (1973), que relacionava a ocorrência de eventos quentes (El Niño) no Equador/Peru com a seca nordestina. Bem como, Hastenrath e 
Heller (1977), Covey e Hastenrath (1978). Cabe, porém, lembrar que Walker (1928) já sugerira a existência de relação entre anomalias da Oscilação Sul e as chuvas no Nordeste. Em vista da ocorrência do evento El Niño de 82/83, até então o mais forte do século, juntamente com uma rigorosa seca em todo o Nordeste brasileiro e outros eventos críticos em diversas partes do mundo, naquele mesmo ano, seguiram-se então muitos outros trabalhos tratando dessa questão.

Uma exposição muito clara sobre o papel conjunto do El Niño e da Oscilação Sul (“ciclo” ENOS/ENSO) encontra-se em Enfield (1989). Sem dúvida, cabe mencionar como fundamentais os artigos de Quinn et al. $(1975,1987)$ a respeito da cronologia dos eventos quentes no Pacífico. E ainda, o trabalho de Moura e Shukla (1981) sobre a dinâmica das secas no Nordeste com base num modelo de circulação geral.

Não vamos discorrer sobre as relações entre a TSM temperatura da superfície do mar no Atlântico intertropical e as chuvas no Nordeste, questão previamente levantada por Markham e McLain (1977) e também por Hastenrath e Heller (1977). Cabe porém mencionar o papel do vento de superfície no Atlântico intertropical, conforme Servain, Picaut et al. (1984, 1985), a tese de Servain (1985), Servain e Seva (1987) como, posteriormente, a tese de Nobre (1993).

A respeito da ZCIT - Zona de Convergência Intertropical, esta é a linha (ou mais exatamente uma faixa) que corresponde à convergência dos ventos tropicais ("trade winds" ou "alíseos") dos hemisférios norte e sul, os quais sopram em média das direções nordeste e sudeste, respectivamente. Trata-se de uma zona de alta instabilidade, pois os ventos que ali convergem ascendem às camadas superiores da atmosfera, dando origem a um cinturão de nuvens identificável através das imagens de satélite.

Sobre o Atlântico intertropical o cinturão de nuvens da ZCIT acha-se usualmente bem organizado, o que não costuma necessariamente ocorrer sobre o Pacífico, em parte devido à maior extensão deste na direção de leste para oeste. Por outro lado, a posição da ZCIT ao longo dos doze meses do ano flutua bastante de um lado e de outro da linha do equador. No Atlântico, ela incursiona bem mais ao norte do equador (entre junho e dezembro) do que ao sul dessa linha (entre janeiro e maio). Sobre o Pacífico dá-se o mesmo, porém com uma flutuação de maior amplitude.

As formações cúmulos-nimbos associadas à ZCIT são responsáveis por fortes chuvas sobre muitas regiões tropicais, como no Brasil, na África, Indonésia, etc. Chuvas mais intensas sobre o Sahel africano (no segundo semestre de cada ano) ou sobre o Nordeste brasileiro (durante o primeiro semestre), ocorrem exatamente naqueles anos em que a ZCIT sobre o Atlântico intertropical incursiona até posições extremas mais ao norte ou, respectivamente, mais ao sul da linha do equador.
Dentre os primeiros estudiosos no Ceará, foi Brasil (1877) quem mais se aproximou de uma explicação coerente para seu clima e a ocorrência de chuvas ou de seca, com base no papel da "zona de calmas tropicais" (a ZCIT), havendo assim se expressado: "Se pelo solstício de dezembro os alíseos param, e reina a calmaria; ou se os ventos variam de rumo ..., entra francamente a estação das chuvas. É principalmente nas proximidades, e depois do equinócio de março, que a estação chuvosa torna-se mais forte e chuvosa”. A rigor, como à época não dispunha de meios observacionais apropriados, suas conclusões foram mais decorrência de haver, intuitivamente, esposado as teorias e as observações de Maury (1855).

A respeito da variabilidade do posicionamento da ZCIT sobre o Atlântico, inclusive para a África tropical, devem ser lembrados os trabalhos de Flohn (1960), Gruber (1972), Frank (1983), Bellec et al. (1984), Citeau et al. $(1985,1988)$ e Dorize (1989). Cabe mencionar que a maioria desses trabalhos baseia-se na análise de imagens para as aglomerações de nuvens acompanhando a zona de convergência dos alíseos. Ilusanmi (1971), para a Nigéria, utilizou uma metodologia com base na linha de descontinuidade entre dados de umidade.

Para o Nordeste, o artigo de McQuate e Hayden (1984) conduzia a resultados discutíveis. Cabe porém mencionar os trabalhos de Uvo (1989) e Mello et al. (2000), tratando das relações da posição da ZCIT no Atlântico com a chuva no Nordeste brasileiro. Bem como, para a Amazônia e ainda o Nordeste, conforme Marengo et al. (1993) e Marengo (1995). Contudo, o papel do posicionamento da ZCIT em março/abril, mais ao norte ou mais ao sul, com respeito a quadras chuvosas mais fracas ou mais fortes no Nordeste, respectivamente, havia já sido considerado por Serra e Ratisbona (1942).

\section{DADOS E METODOLOGIA}

\section{Bacias e Séries Pluviométricas}

As 6 (seis) bacias consideradas no presente artigo constam da Figura 1, a saber: 1. Bacia do Coreaú (com sete postos pluviométricos); 3. Bacia do Acaraú (doze postos); 6. Bacia Metropolitana (dezessete postos); 8. Bacia do Banabuiú (oito postos); 10. Bacia do Alto Jaguaribe (catorze postos); 11. Bacia do Salgado (onze postos).

Remete-se a Xavier et al. (1999), op. cit., para o rol dos postos pluviométricos empregados no cálculo das médias da chuva, mensalmente, sobre as referidas bacias hidrográficas, juntamente com suas localizações geográficas (latitude e longitude) e altitude.

De fato, na mencionada Figura 1, essas bacias correspondem às áreas em cinza sobre uma carta do Estado do Ceará e, por simples inspeção, depreende-se que sua área cobre a maior parte da extensão geográfica estadual. Para 


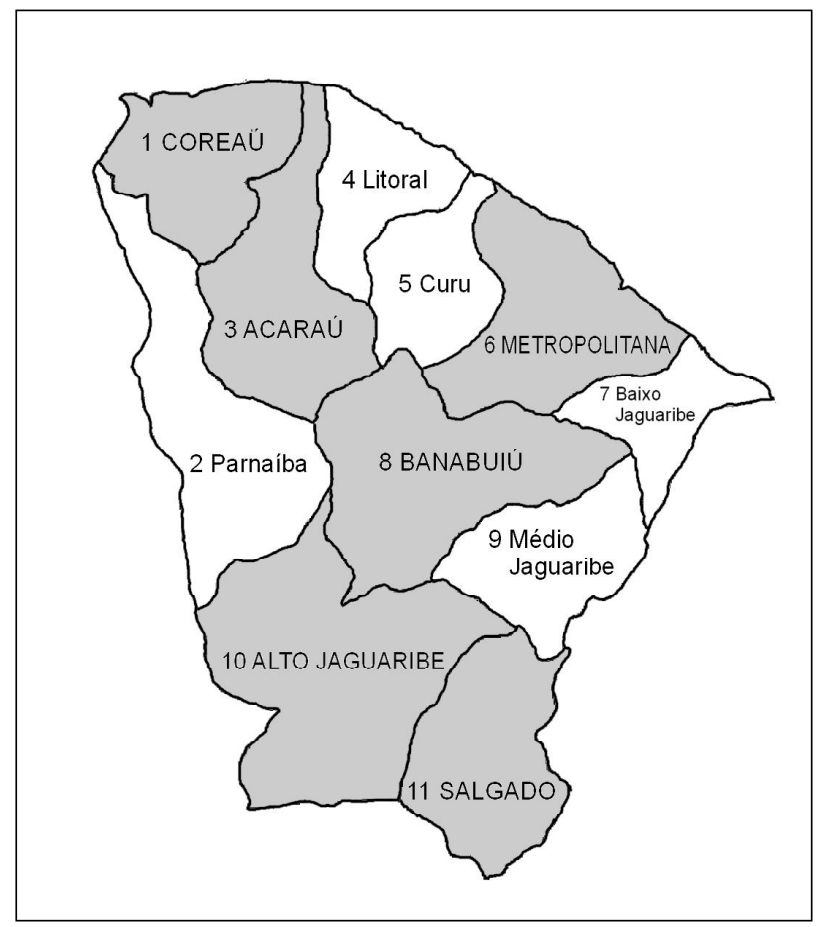

Figura 1. Bacias hidrográficas no estado do Ceará (em cinza as usadas neste trabalho).

maiores informações sobre as características dessas bacias podem ser consultados trabalhos técnicos, entre os quais: Macedo (1981) e Estado do Ceará/SRH - SOHIDRA FUNCEME (1992).

Foram utilizadas séries pluviométricas para o período 1964-1999, devidamente consistidas; a saber, séries "híbridas" obtidas daquelas extraídas dos bancos de dados ou arquivos da SUDENE, do DNAEE e da FUNCEME, perfazendo o total de 93 (noventa e três) postos. A tarefa de organização dessa "base de dados" deve-se ao primeiro autor, com a colaboração do segundo, conforme Xavier e Xavier $(1998,1999)$ e Xavier (2001).

\section{Dados da pseudo-tensão do vento no Atlântico}

Tornou-se necessário dispor dos dados mensais da componente meridional da "pseudotensão" do Vento-TSV no Atlântico, cedidos pelo Prof. Dr. Jacques Servain, do IRD (antiga ORSTOM) - Centro da Bretanha. Os dados para a "pseudotensão" do vento, em termos de suas componentes meridional e zonal, cobrem extensa área sobre o Atlântico, entre $30^{\circ} \mathrm{N}$ e $20^{\circ} \mathrm{S}$, e entre $60^{\circ} \mathrm{W}$ e $16^{\circ} \mathrm{E}$, correspondentes ao período 1964-98 e, ainda, aos primeiros meses de 1999 (janeiro, fevereiro e março), em pontos de grade de dois em dois graus. Não obstante, são mensalmente atualizados, de sorte que já se encontram disponíveis para todo o primeiro semestre de 2002, momento em que a versão final deste artigo foi concluída. A análise não foi porém estendida para todo o período de 1964 a 2002, por dois motivos principais; em primeiro lugar, porque importaria num retardo injustificável, depois, pela circunstância de que os resultados no contexto desta pesquisa não ficariam significativamente alterados.

Esses dados do vento são obtidos de navios cruzando o Atlântico (juntamente com dados da TSM) e tratados no Centro da Bretanha-IRD. Originariamente, através de uma parceria entre a Universidade da Bretanha Ocidental-França e a Universidade do Hawai-USA, conforme Picaut, Servain et al. (1985). Note-se que para os propósitos desta pesquisa é irrelevante que se trabalhasse com a "intensidade do vento" ou sua "pseudotensão". Com efeito, são em princípio coincidentes os pontos em que se anulam esses vetores ou as suas componentes meridionais.

\section{Cronologia de episódios ENOS}

Quanto à cronologia de eventos ENOS/ENSO, lança-se mão dos levantamentos expostos em Xavier et al. (2000b, c) e Xavier (2001), com base nos dados do Índice de Oscilação Sul de Troup; bem como, da série do "JMAIndex" (da Agência Japonesa de Meteorologia) para as anomalias da TSM - temperatura da superfície do Pacífico na área delimitada por $4^{\circ} \mathrm{N}-4^{\circ} \mathrm{S}$ e $150^{\circ} \mathrm{W}-90^{\circ} \mathrm{W}$, de acordo com a Figura 2.

Assim, a respeito da cronologia desses eventos os autores utilizam conclusões, extraídas de uma análise gráfica e estatística conjunta das duas séries de dados históricos. Tal procedimento foi julgado indispensável pois, na literatura científica, é possível flagrar a esse respeito, não apenas inconsistências e imprecisões mas, por vezes, até lapsos ou erros flagrantes. Ver em Xavier et al. (2000b) e particularmente Xavier (2001), op. cit., comparações com as cronologias do COAPS - "Center for Ocean-Atmospheric Prediction

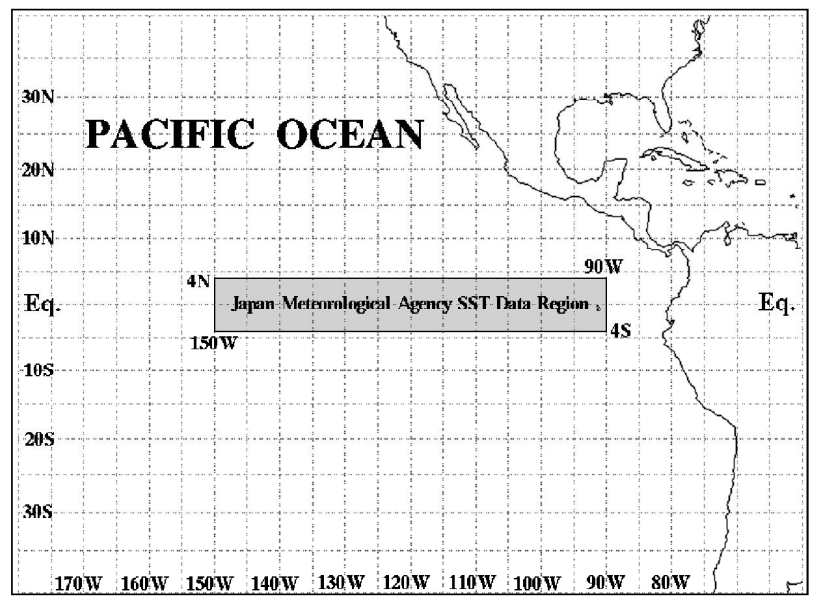

Figura 2. Área para o índice da TSM no pacífico equatorial (conforme reprodução de uma carta original da área da JMA - Japanese Meteorological Agency). 
Studies" e de Quinn et al. (1987); bem como, ainda, com aquelas divulgadas em outras fontes diversas.

\section{Metodologia}

Tratamento dos dados de chuva - Para cada uma das bacias, a chuva foi expressa em termos das médias mensais, com referência aos anos consecutivos de 1964 a 1999. Considerou-se que tal procedimento seria aceitável para um estudo preliminar, muito embora não estivesse assegurada, "a priori", uma cobertura uniforme através dos postos pluviométricos disponíveis. Então, relativamente a cada bacia e à "quadra chuvosa" (fevereiro-maio), calcularam-se seus "quantis" a partir dos dados para o período 1964-96, com respeito às “ordens quantílicas" $\mathrm{p}=0,15 ; 0,35 ; 0,65 ; 0,85$. Esses quantis são aqui representados por Q $(0,15) ; \mathrm{Q}(0,35) ; \mathrm{Q}(0,65) ; \mathrm{Q}(0,85)$. Assim, dado um valor $\mathrm{X}_{\mathrm{i}}$ da chuva, durante a "quadra chuvosa" do ano i, considera-se que este valor corresponderá a uma das cinco classes seguintes: $-2=\mathrm{MS}=$ muito seco; $-1=\mathrm{S}=\operatorname{seco} ; 0=\mathrm{N}=$ normal; $1=\mathrm{C}=$ chuvoso; $\mathrm{e}$ $2=\mathrm{MC}=$ muito chuvoso; conforme então se verifique, respectivamente: $\mathrm{X}_{\mathrm{i}}<\mathrm{Q}(0,15) ; \mathrm{Q}(0,15)<\mathrm{X}_{\mathrm{i}}<\mathrm{Q}(0,35)$; $\mathrm{Q}(0,35)<\mathrm{X}_{\mathrm{i}}<\mathrm{Q}(0,65) ; \mathrm{Q}(0,65)<\mathrm{X}_{\mathrm{i}}<\mathrm{Q}(0,85) ;$ e $\mathrm{X}_{\mathrm{i}}>\mathrm{Q}(0,85)$.

A técnica dos "quantis" foi utilizada no trabalho pioneiro de Pinkayan (1966). Depois, numa seqüência de trabalhos de Xavier e Xavier (1984a, 1984b, 1987a, 1987b, 1989, 1990), tal metodologia foi então aplicada para o problema da classificação e monitoração da ocorrência de anos secos ou chuvosos no Nordeste Brasileiro e, em particular, no Estado do Ceará. Uma revisão muito detalhada quanto a todos os aspectos metodológicos dessa técnica encontra-se em Xavier e Xavier (1998, 1999), Xavier (2001) e Xavier et al. (2002a, 2002b).

Determinação da posição da ZCIT - Para determinar o posicionamento da ZCIT com relação à linha equatorial, emprega-se a metodologia desenvolvida em Xavier e Xavier (1997) e Xavier et al. (1997, 1998), com base na definição básica, ou seja, como a linha ou faixa de convergência dos alíseos. Lembremos que Picaut e Servain (1985) já mencionavam que a ZCIT fica materializada em termos do mínimo (zero) do valor absoluto da componente meridional do vento ou, como no nosso caso, correspondendo aos pontos sobre os meridianos consecutivos, onde essa componente troca de sinal (convencionada como negativa no sentido $\mathrm{N} \rightarrow \mathrm{S}$ e positiva no sentido $S \rightarrow N$ ).

Ademais, além da representação da posição global da ZCIT na bacia do Atlântico intertropical, podem também ser obtidas séries numéricas das posições latitudinais médias da convergência, com respeito a um dado meridiano, via um algoritmo simples de interpolação dos valores da com-

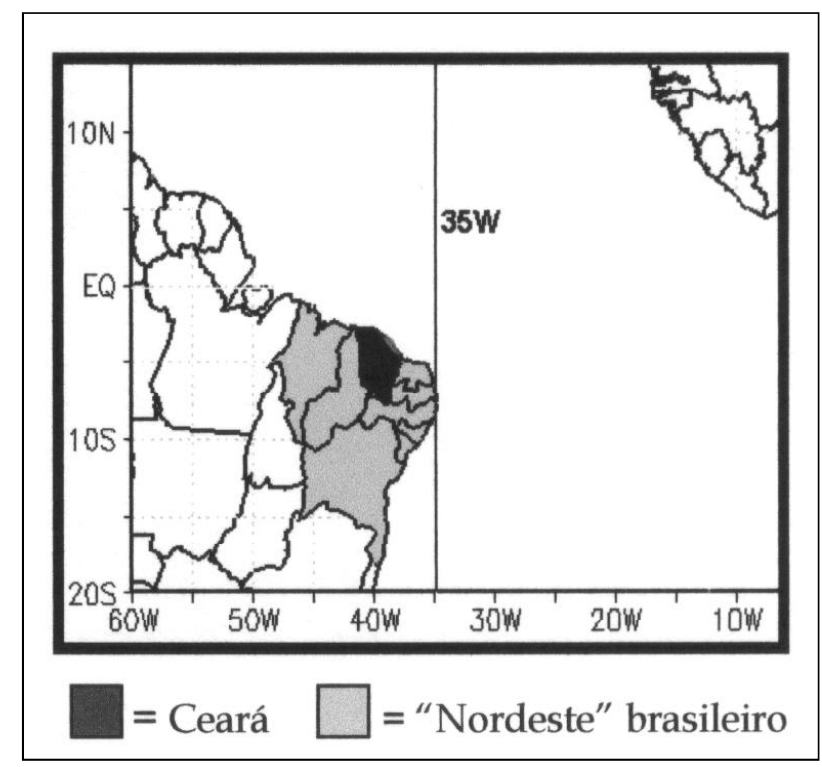

Figura 3. Meridiano $35^{\circ} \mathrm{W}$ ("Ponta de Seixas PB" = 34'30"W).

ponente meridional do vento. Essas séries são obviamente calculadas ao longo do meridiano que tenha sido previamente definido, mediante a fixação de uma longitude arbitrariamente escolhida. Em particular, aqui, são considerados os meridianos $37^{\circ} \mathrm{W}$ e $35^{\circ} \mathrm{W}$ (este quase na linha que tangencia a costa leste do Nordeste-Brasil, na Ponta de Seixas-PB, o ponto mais oriental de todo o território brasileiro, a saber $\left.34^{\circ} 47^{\prime} 30^{\prime \prime} \mathrm{W}\right)$.

$\mathrm{Na}$ Figura 3 tem-se a indicação, numa carta, a essa posição do meridiano $35^{\circ} \mathrm{W}$, com respeito à costa leste do Nordeste brasileiro.

Note-se a Figura 4 com a evolução da posição latitudinal da ZCIT sobre o referido meridiano de $35^{\circ} \mathrm{W}$, entre janeiro de 1964 e maio de 1997, revelando que, de fato, ficou próxima (porém um pouco mais ao sul) da latitude $16^{\circ} \mathrm{N}$ na sua posição alcançada mais ao norte, bem como, atingindo na sua incursão mais ao sul do equador um ponto próximo a $7^{\circ} \mathrm{S}$. Por outro lado, na Figura 5, o mesmo gráfico foi recortado para o intervalo janeiro de 1974 a janeiro de 1984, quando se denota que no período 1978-1983, em termos das suas posições latitudinais mais baixas, quase não passou ao sul da linha do equador (observação essa que se torna bem sintomática pois 1979-83 correspondente a cinco anos históricos de seca no Nordeste). No caso específico destes dois gráficos, trabalhou-se com o meridiano $35^{\circ} \mathrm{W}$ para fins de garantir a determinação da posição da ZCIT, sobre o Atlântico, sem interferência continental.

De fato, a seguir, trabalhar-se-á exclusivamente com respeito à posição da ZCIT sobre o meridiano de $37^{\circ} \mathrm{W}$, que corta o território do Ceará próximo a Fortaleza. Note-se que latitudes ao norte da linha do equador serão consideradas positivas (+) e, ao sul, negativas (-). 


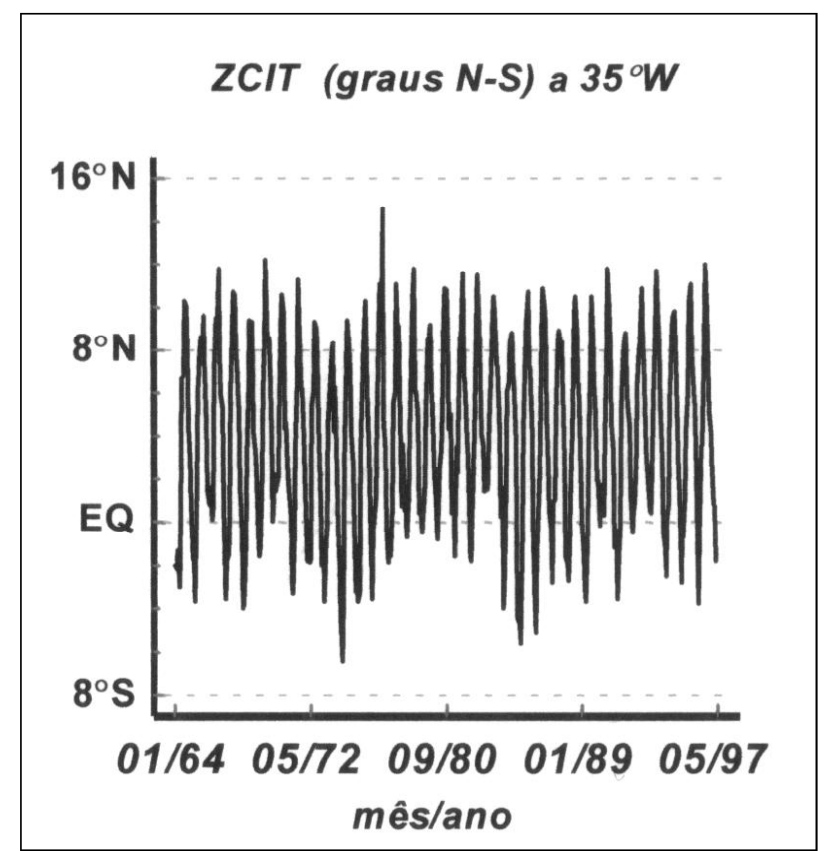

Figura 4. Posições latitudinais da ZCIT sobre o meridiano $35^{\circ} \mathrm{W}$ entre $01 / 64$ e $05 / 97$.

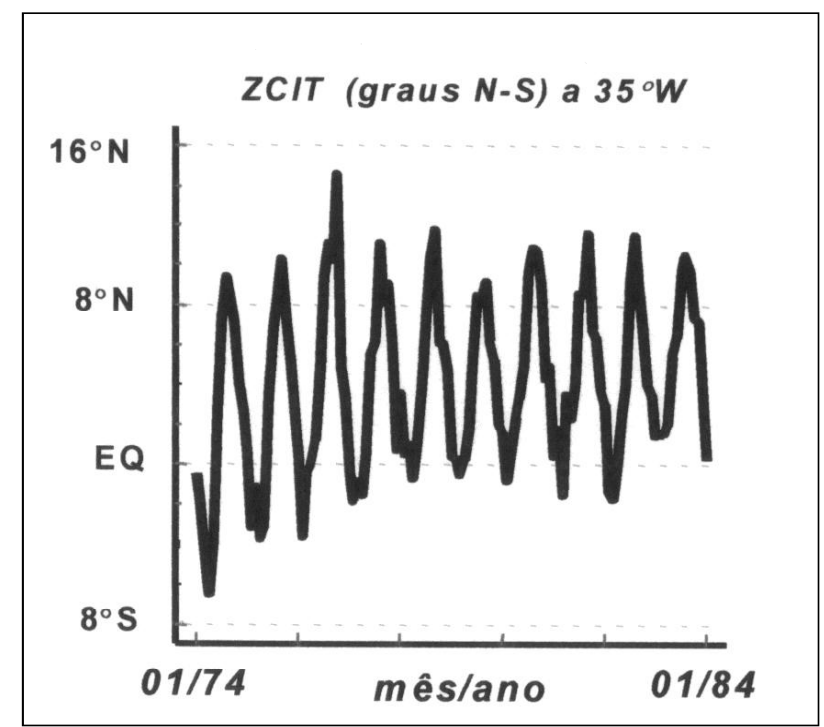

Figura 5. Posições latitudinais da ZCIT sobre o meridiano $35^{\circ} \mathrm{W}$ entre $01 / 74$ e $01 / 84$.

Classificação dos eventos ENOS - Quanto aos eventos ENOS, utilizou-se uma classificação simplificada, a saber: -1 = ocorrência de LA NIÑA, 0 = "ano neutro" e 1 = ocorrência de EL NIÑO. Para as ocorrências de "El Niño" foram levados em conta apenas aqueles anos i em que o fenômeno ocorreu ou persistiu até aos primeiros meses dos referidos anos, ou seja, os eventos i- $1 /$ i ou */i, sendo portanto descartados (ou tratados como "neutros") os anos i-1/*; conforme as notações utilizadas em Xavier et al. (1995), Xavier et al. (2000b) e Xavier (2001), sob a forma i-1/i, em que i refere-se à ocorrência do fenômeno EN ("EL
Niño") no $1^{\circ}$ semestre de um dado ano i, enquanto i- 1 a sua ocorrência no $2^{\circ}$ semestre precedente; por sua vez $*$ significa sua não ocorrência no semestre correspondente. Note-se que a notação básica i-1/i foi introduzida com base nas observações contidas no artigo de Aceituno (1992).

Análise de variância - Como será visto, começa-se pela análise da influência das ocorrências de eventos ENOS com respeito à chuva acumulada durante a "quadra chuvosa" ou quadrimestre fevereiro-maio nas bacias hidrográficas, bem como, com respeito à posição média da ZCIT no referido período chuvoso, considerando para essa finalidade as "classes" -1 = "La Niña", 0 = "ano neutro" e 1 = "El Niño".

Em seguida, passa-se à análise da relação entre a chuva numa bacia e a posição latitudinal da ZCIT, relativamente à linha do equador, mês a mês, que se empreende mediante análises de variância para as variáveis Z3701 a Z3706 (posições da ZCIT no meridiano $37^{\circ} \mathrm{W}$, de $01=$ janeiro a $06=$ junho), com respeito às "classes" -2 = MS (muito seco), $-1=\mathrm{S}$ (seco), $0=\mathrm{N}$ (normal), $1=\mathrm{C}$ (chuvoso) e $2=\mathrm{MC}$ (muito chuvoso) relativas à chuva acumulada na bacia durante a "quadra chuvosa" (fevereiro-maio). De forma análoga, previamente, empreende-se a análise de variância para a posição latitudinal média da ZCIT no quadrimestre fevereiromaio, com respeito às mesmas classes. De fato, deve ser realizada "a priori" tal classificação para a chuva em cada bacia, a partir de 1964, para a definição dessas classes.

Para melhor entendimento do leitor, lembramos que a Análise de Variância é um procedimento estatístico destinado a comparar as médias de $\mathrm{k}>2$ amostras; no caso, correspondentes às $\mathrm{k}=5$ classes definidas a partir $\mathrm{da}$ pluviometria na quadra chuvosa (de "muito seco" até "muito chuvoso") ou às $\mathrm{k}=3$ classes definidas para eventos ENOS/ENSO (EN = El Niño, LN = La Niña e "ano neutro no Pacífico"). Assim, serão para essas classes que se compararam os valores numéricos das posições latitudinais da ZCIT ou de uma outra variável de interesse. Na verdade, caberá não confundir a variável envolvida nas comparações (por exemplo a posição da ZCIT) com a variável eventualmente utilizada para a definição das classes (por exemplo, a chuva).

De fato, a Análise de Variância constitui uma generalização do conhecido teste $t$ de Student para comparação de duas amostras. Aliás, para $\mathrm{k}=2$, prova-se (matematicamente) que tal procedimento multivariado recai no teste $t$.

As saídas tradicionais obtidas através dos programas computacionais para uma análise de variância fornecem, em primeiro lugar a tabela que sumariza o procedimento propriamente dito ou "tabela da análise de variância". Esta, aliás, que costuma ser menos compreensível ao leigo, à parte da informação sobre o nível de significância e a probabilidade de erro envolvido no teste. Porém, essas saídas costumam oferecer outras informações relevantes, todas de fácil entendimento, entre as quais a tabela das médias numéricas 
Tabela 1. Análise de variância para a chuva na Bacia Metropolitana, de fevereiro a maio, incluindo os valores da chuva média e seus intervalos de confiança, conforme o estado do pacífico equatorial (ind_enos: $-1=$ anos de "La Niña", $0=$ anos “neutros" e 1 = de "E1 Niño").

\begin{tabular}{lccccc}
\hline \multicolumn{2}{c}{ Dados: $\mathrm{m} 0 \mathrm{~h} \_\mathrm{fm}=$ chuva na Bacia Metropolitana em fev-mai } & \multicolumn{2}{c}{ Classes: ind_enos } \\
Origem da variação & Soma de quadrados & gdl* & Média dos quadrados & razão-F & Nível de significância** \\
\hline Entre classes & 613656,7 & 2 & 306828,34 & 4,041 & $\mathrm{p}=0,027$ \\
Intra classes & 2429740,0 & 32 & 75929,38 & & \\
Total & 3043396,7 & 34 & & & \\
\hline
\end{tabular}

* Graus de liberdade; ** Probabilidade de erro.

Tabela 2. Valores médios e intervalos de confiança $95 \%$ para m0h_fm (chuva na Bacia Metropolitana em fev.-mai.) em função de ind_enos.

\begin{tabular}{ccrc}
\hline $\begin{array}{c}\text { Classe } \\
\text { ind_enos }\end{array}$ & $\begin{array}{c}\text { \# de } \\
\text { observações }\end{array}$ & $\begin{array}{c}\text { Chuva média } \\
(\mathrm{mm})\end{array}$ & $\begin{array}{c}\text { Intervalos de } \\
\text { confiança 95\% para } \\
\text { as médias (mm) }\end{array}$ \\
\hline-1 & 7 & $1.070,61$ & $920,57-1.220,66$ \\
0 & 16 & 928,58 & $829,34-1.027,83$ \\
1 & 12 & 716,15 & $601,55-830,75$ \\
Total & 35 & 884,15 & \\
\hline
\end{tabular}

observadas para as várias classes e os respectivos intervalos de confiança, bem como, sua representação gráfica.

Apesar da Análise de Variância Clássica ser um teste considerado robusto, podem ser tomadas algumas precauções, tais como: (i) realização de testes para a homogeneidade da variância no contexto de cada análise (testes de Cochran e de Bartlett); (i) idem, de testes de normalidade; (iii) realização de uma Análise de Variância não-paramétrica (ou teste de Kruskal-Wallis) quando isso for indicado para dirimir dúvidas.

Deve ser lembrado, outrossim, que através de uma análise de variância obtém-se, unicamente, informação sobre o comportamento global das médias com respeito às várias classes. Assim, quando da rejeição da "hipótese nula", apenas se sabe que os grupos não podem ser considerados "iguais" ou provenientes de uma mesma "população", porém, não é fornecido em princípio qualquer informe a respeito da exata localização das eventuais diferenças entre as médias e, em especial, sobre sua significância. Para esse fim, devem então ser empregados testes suplementares de comparações múltiplas (como aquele mais simples, baseado no desvio mínimo ou LSD, ou ainda o de Tukey, de Scheffé, etc.).

Todas as precauções acima referidas foram tomadas, no contexto deste trabalho. Porém, a maioria dos resultados dos testes complementares será omitida para fins de não sobrecarregar o texto ou as conclusões apresentadas, ou seja, no sentido de evitar uma pletora de informações muito técnicas que poderiam tão somente confundir o leitor. Contudo, serão sempre exibidos os níveis de significância para as análises efetuadas, em termos das suas probabilidades $\mathrm{p}$ de

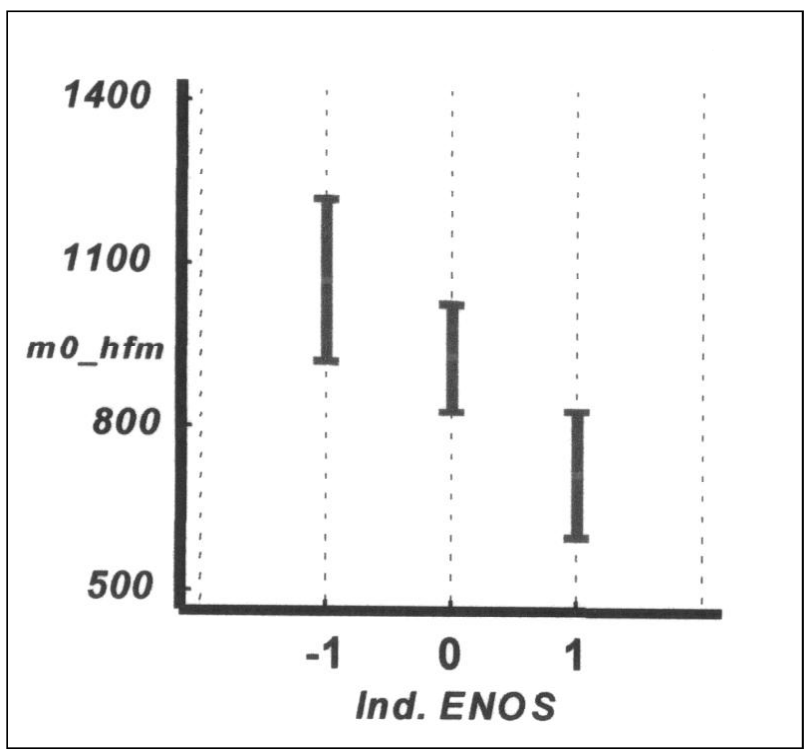

Figura 6. Intervalos de confiança para a chuva $(\mathrm{em} \mathrm{mm})$ na Bacia Metropolitana acumulada durante o quadrimestre fevereiro-maio ( $\left.\mathrm{m} 0 \mathrm{~h} \_\mathrm{fm}\right)$ na dependência de episódios do “ciclo" ENOS (Ind. ENOS: - 1 = La Niña, 0 = ano neutro, $1=$ El Niño).

erro, além da reprodução dos já mencionados gráficos com os "intervalos de confiança" das médias, para as várias classes.

O leitor que desejar conhecer e dominar esta técnica estatística poderá, livremente, consultar obras clássicas ou modernas de estatística. Porém um tratamento bastante claro encontra-se no livro de Guenther (1965, 1973, $2^{\circ}$ ed.), bem como, em Chatfield (1970, 1983, $3^{\circ}$ ed.). Para os métodos não-paramétricos, a referência básica é Conover (1971, 1999, $3^{\circ}$ ed.). Em Sachs (1978) dispõe-se de uma apresentação e um tratamento suficientemente completos, tanto sobre o método clássico da Análise de Variância e seus testes complementares, quanto acerca de procedimentos nãoparamétricos. $\mathrm{Na}$ área climática, específica, remete-se a Essenwanger (1986).

Note-se que para o estudo e detecção de mudanças climáticas a Análise de Variância pode ser um procedimento de eleição, empregando-se neste caso, como "classes", intervalos de tempo consecutivos; ver Xavier et al. (1994), 
Tabela 3. Análise de variância para a chuva na Bacia do Alto Jaguaribe, de fevereiro a maio, incluindo os valores da chuva média e seus intervalos de confiança, conforme o estado do pacífico equatorial (ind_enos: $-1=$ anos de "La Niña", $0=$ anos “neutros" e 1 = de “E1 Niño").

\begin{tabular}{lccccc}
\hline \multicolumn{2}{c}{ Dados: j1h_fm $\begin{array}{c}\text { c chuva na Bacia do Alto Jaguaribe em fev-mai } \\
\text { Intervalos de confiança a 95\% }\end{array}$} & \multicolumn{2}{c}{ Classes: ind_enos } \\
Origem da variação & Soma de quadrados & gdl* & Média dos quadrados & razão-F & Nível de significância** \\
\hline Entre classes & 267758,6 & 2 & 133879,32 & 4,594 & $\mathrm{p}=0,018$ \\
Intra classes & 932621,0 & 32 & 29144,41 & & \\
Total & 1200379,6 & 34 & & & \\
\hline
\end{tabular}

* Graus de liberdade; ** Probabilidade de erro.

Tabela 4. Valores médios e intervalos de confiança $95 \%$ para j1h_fm (chuva na bacia do Alto Jaguaribe em fev.mai.) em função de ind_enos.

\begin{tabular}{cccc}
\hline $\begin{array}{c}\text { Classe } \\
\text { ind_enos }\end{array}$ & $\begin{array}{c}\text { \# de } \\
\text { observações }\end{array}$ & $\begin{array}{c}\text { Chuva média } \\
(\mathrm{mm})\end{array}$ & $\begin{array}{c}\text { Intervalos de } \\
\text { confiança 95\% para } \\
\text { as médias (mm) }\end{array}$ \\
\hline-1 & 7 & 675,09 & $582,13-768,04$ \\
0 & 16 & 557,83 & $496,35-619,32$ \\
1 & 12 & 433,94 & $362,94-504,38$ \\
Total & 35 & 538,81 & \\
\hline
\end{tabular}

Xavier et al. (1996) e Xavier e Xavier (1996). Nesse contexto, tal procedimento de análise poderá ser conjugado com técnicas de séries temporais, etc.

\section{RESULTADOS}

\section{O papel do Pacífico sobre a chuva nas bacias e sobre a posição média da ZCIT}

Nas Figuras 6 e 7 avalia-se a influência de eventos ENOS (-1 = ano de "La Niña", 0 = ano neutro, 1 = ano de "El Niño") sobre a chuva nas bacias Metropolitana e do Alto Jaguaribe, ou seja, a primeira delas litorânea e a outra situada no extremo sul do Estado do Ceará. Como se pode perceber pela inspeção das referidas figuras, a chuva média nas duas bacias durante a "quadra chuvosa" decresce, progressivamente, com respeito às classes de anos de "La Niña", "neutros" e de "El Niño". Note-se bem, nestas duas figuras, que a variável submetida à análise de variância é a chuva nas bacias, enquanto as três modalidades de eventos no Pacífico equatorial definem as $\mathrm{k}=3$ classes de anos envolvidas.

Os resultados numéricos para as análises de variância respectivas comparecem nas Tabelas 1 e 2 , no caso da Bacia Metropolitana, nas Tabelas 3 e 4, com respeito à Bacia do Alto Jaguaribe. Por essas tabelas denota-se que as probabilidades de erro são da ordem de $\mathrm{p}=0,03$ e $\mathrm{p}=0,02$ respectivamente; portanto, inferiores a $5 \%$. As tabelas também mostram os valores para a chuva média, com respeito às

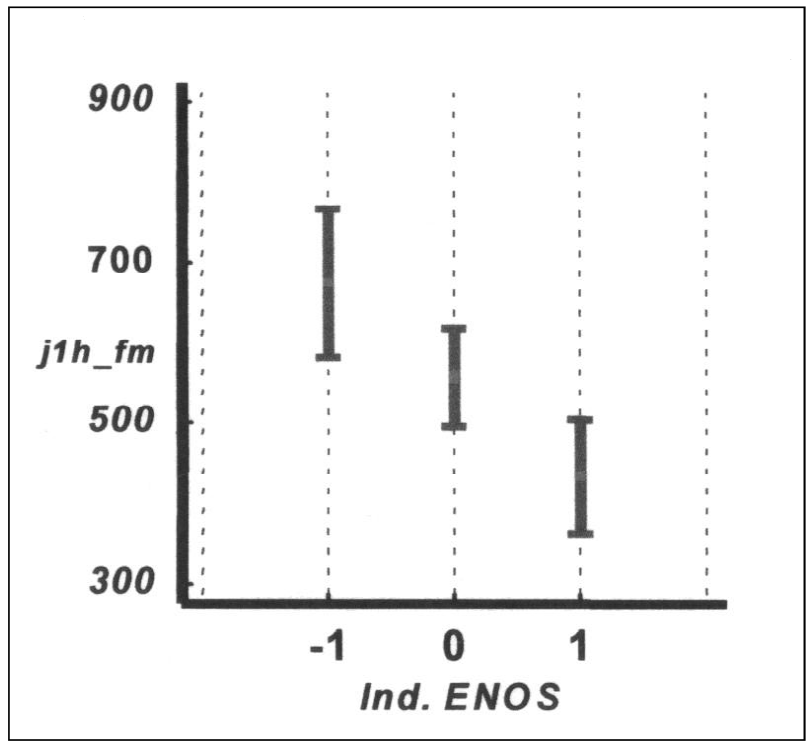

Figura 7. Intervalos de confiança para a chuva (em $\mathrm{mm})$ na Bacia do Alto Jaguaribe acumulada durante o quadrimestre fevereiro-maio (j1h_fm) na dependência de episódios do “ciclo" ENOS (Ind. ENOS: -1 = La Niña, 0 = ano neutro, $1=$ El Niño).

ocorrências dos eventos ENOS, juntamente com os respectivos intervalos de confiança.

Por outro lado, na Figura 8 verifica-se muito claramente a tendência da posição média da ZCIT na "quadra chuvosa", ao longo do meridiano de $37^{\circ} \mathrm{W}$, de permanecer em torno (ou próxima) da linha equatorial nos anos $1=$ "El Niño", enquanto alcança posições progressivamente mais ao sul daquela linha e mais próximas do Nordeste setentrional e do Ceará, nos anos $0=$ "neutros" e - 1 = de "La Niña". Neste caso, o nível de significância da Análise de Variância é dado pela probabilidade de erro $\mathrm{p}=0,0017$ (portanto inferior a 2 por mil). São omitidas as tabelas respectivas. Mas se pode ainda adiantar que, em anos de "El Niño", a média da posição ZCIT durante a quadra chuvosa está dentro do intervalo de confiança que vai de 0,72 graus sul a 0,42 graus norte, portanto, em torno da linha do equador; enquanto para anos de "La Niña", indo de 2,0 graus sul a 3,5 graus sul. 


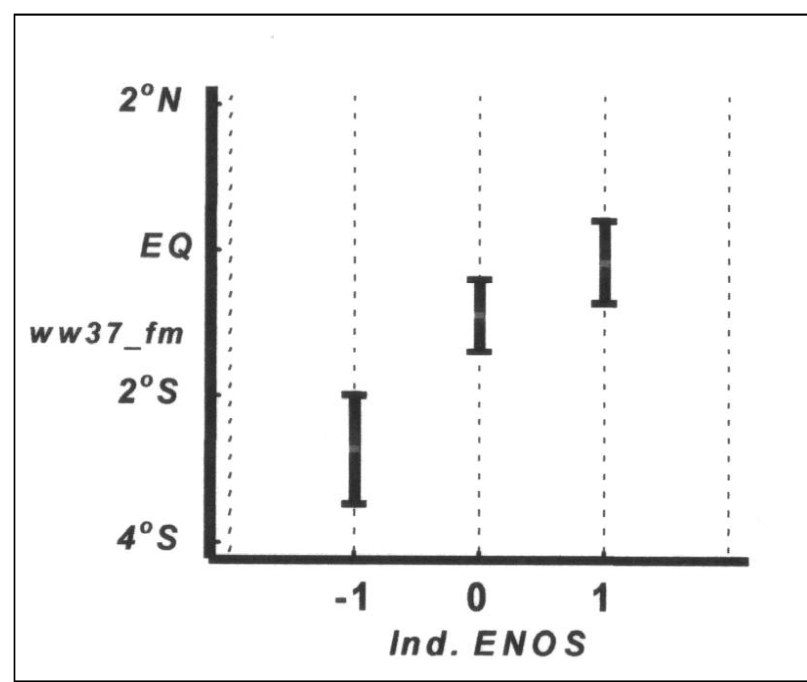

Figura 8. Posição latitudinal média da ZCIT ao longo do meridiano $37^{\circ} \mathrm{W}$, durante a "quadra chuvosa" = fevereiromaio, em função da classificação dos anos, dada por Ind_ENOS: -1 = La Niña, 0 = anos "neutros" e 1 = E1 Niño; $E Q$ = equador.

\section{Relação entre a posição média da ZCIT e a} chuva nas bacias durante a "quadra chuvosa"

Por outro lado, na Figura 9, têm-se as posições médias da ZCIT na "quadra chuvosa", em função dos anos para os quais a chuva acumulada no período na Bacia Metropolitana classificou-se nas categorias $-2=$ muito seco, $-1=$ seco, $0=$ normal, $1=$ chuvoso e $2=$ muito chuvoso, concluindo-se que essas posições médias localizam-se, progressivamente, cada vez mais ao sul da linha equatorial em função do aumento da chuva.

Note-se, com respeito ao que ficou constatado para a Bacia Metropolitana, situada no litoral, conforme a Figura 9 precedente, que o mesmo também ocorre no caso da Bacia do Alto Jaguaribe, de acordo com a Figura 10. Esta última bacia, interiorana, está localizada no sul do Estado do Ceará, conforme mostra o mapa da Figura 1 que traz a distribuição espacial das bacias hidrográficas. Assim, demonstra-se que a relação da ZCIT com a "quadra chuvosa" é prevalente no que diz respeito a todo o território cearense. Ademais, cabe mencionar que isso também se constata para o caso das demais bacias.

$\mathrm{Na}$ secção seguinte vai-se ainda explorar, com mais detalhes, a questão do posicionamento da ZCIT durante a "quadra chuvosa" no Ceará, nas várias bacias, em termos de um acompanhamento, mês a mês.

Relação da posição média da ZCIT, mês a mês, de janeiro a junho, com a chuva na bacia metropolitana

Como foi visto mediante a inspeção das duas Figuras 9 e 10, tornou-se evidente que a posição média da ZCIT

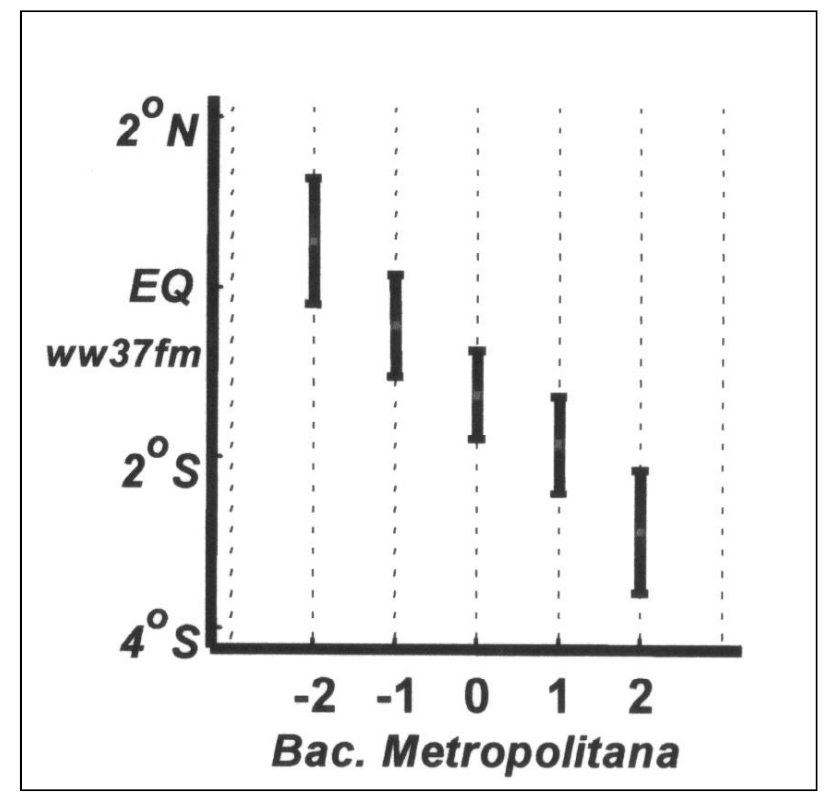

Figura 9. Posição média da ZCIT ao longo de $37^{\circ} \mathrm{W}$ na "quadra chuvosa" (fevereiro-maio) segundo as categorias para a chuva $(-2=$ muito seco, $-1=$ seco, $0=$ normal, $1=$ chuvoso, $2=$ muito chuvoso) na Bacia Metropolitana. $\mathrm{EQ}=$ equador.

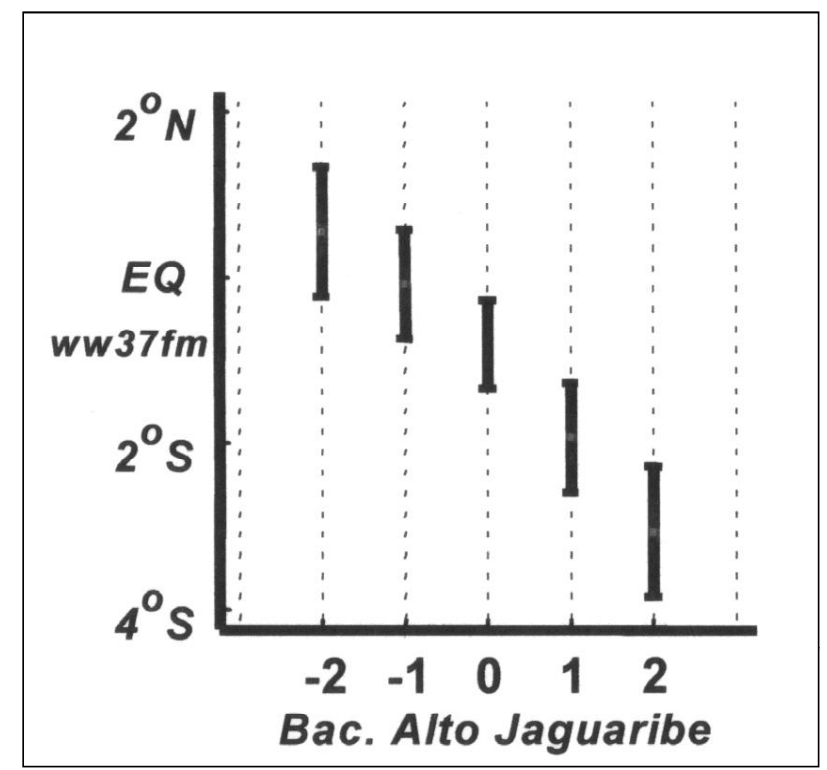

Figura 10. Posição média da ZCIT ao longo de $37^{\circ} \mathrm{W}$ na “quadra chuvosa" (fevereiro-maio) segundo as categorias para a chuva $(-2=$ muito seco, $-1=\operatorname{seco}, 0=$ normal, $1=$ chuvoso, $2=$ muito chuvoso) na Bacia do Alto Jaguaribe. $E Q=$ equador.

durante a quadra usualmente mais chuvosa no Ceará (fevereiro-maio) passa a ocupar posições cada vez mais ao sul da linha equatorial, segundo as chuvas ocorram nas categorias: $-2=$ muito seco, $-1=\operatorname{seco}, 0=$ normal, $1=$ chuvoso $\mathrm{e}$ 2 = muito chuvoso, consideradas tais categorias ou classes, 
tomadas nessa ordem. Reexamina-se agora o mesmo processo, porém separadamente para meses consecutivos. Ou seja, levando em conta as posições alcançadas pela ZCIT com relação à linha equatorial, em cada mês, de janeiro até junho, segundo as categorias (ou classes) para a chuva, acumulada durante todo o período fevereiro-maio, na Bacia Metropolitana.

Assim, na Figura 11, são exibidos os 6 (seis) gráficos que correspondem aos meses de janeiro até junho e, para cada mês, ficaram representados os intervalos de confiança das posições latitudinais da ZCIT ao longo do meridiano $37^{\circ} \mathrm{W}$. Note-se que em cada um desses gráficos comparecem os cinco intervalos de confiança da posição da ZCIT no mês, para cada uma das classes: $-2=$ MS (muito seco) $-1=\mathrm{S}$ (seco), $0=\mathrm{N}$ (normal), $1=\mathrm{C}$ (chuvoso) e $2=\mathrm{MC}$ (muito chuvoso), referentes à chuva acumulada na bacia durante a "quadra chuvosa".

De uma primeira inspeção dessa figura denota-se, claramente, a respeito das posições médias da ZCIT sobre o meridiano de $37^{\circ} \mathrm{W}$, acima (ao norte) ou abaixo (ao sul) da linha do equador, de janeiro até junho:

1. Em Janeiro, essa posição média (ponto médio do segmento que representa o intervalo de confiança) situa-se ao norte da linha equatorial, para as três classes $-2=\mathrm{MS}$ (muito seco), $-1=\mathrm{S}$ e $0=\mathrm{N}$; passando um pouco ao sul dessa linha para a classe $1=\mathrm{C}$ (chuvoso); enquanto para a classe $2=\mathrm{MC}$ (muito chuvoso) alcança uma posição próxima de $-1,5^{\circ}$ (ou seja $1,5^{\circ} \mathrm{S}$, portanto, já nitidamente ao sul do equador). De fato, para este mês, o nível de significância é p = 0,14 (logo há uma probabilidade da ordem de $15 \%$ para que tal resultado pudesse dever-se ao puro acaso, em termos da análise de variância clássica). Não obstante, o fato das médias para as posições da ZCIT decrescerem progressivamente desde a classe $-2=$ MS até à classe $2=\mathrm{MC}$, é uma indicação de que tais resultados são provavelmente legítimos, isto é, que a partir dos anos muito secos até aos muito chuvosos, já em janeiro, a ZCIT situa-se progressivamente (em termos médios) em latitudes cada vez mais próximas do Ceará. Na verdade, um teste de comparações múltiplas mostra que $\{-2,-1,0\}$ (muito seco a normal) é um grupo homogêneo que difere significativamente da classe $\{2\}$ (muito chuvoso).

O resultado para a Análise de Variância com respeito à posição da ZCIT no mês de Janeiro, relativamente às cinco classes da chuva no quadrimestre fevereiro-maio, sobre a Bacia Metropolitana, é exibida na Tabela 5. Por outro lado, resultados para um teste de comparações múltiplas são mostrados na Tabela 6. Omitem-se as tabelas correspondentes aos demais meses.

2. Já em Fevereiro, a posição média da ZCIT mantém-se ao norte da linha do equador apenas para a classe $-2=$ MS; ao passo que, para todas as demais classes de anos, desde $-1=\mathrm{S}$ até $2=\mathrm{MC}$, a ZCIT sobre o meridiano de $37^{\circ} \mathrm{W}$ posiciona-se em média ao sul da linha equatorial e em latitudes progressivamente cada vez mais próximas do Ceará; assim, nos anos na categoria $2=\mathrm{MC}$ (muito chuvoso), essa posição média fica em torno (aproximadamente) de $-3,7^{\circ}$ (ou $3,7^{\circ} \mathrm{S}$ ). Por outro lado, o resultado da Análise de Variância é significativo, com p $=0,028<5 \%$.

3. Em Março, o comportamento é análogo ao do mês anterior. Contudo, ocorre a circunstância que a Análise de Variância passa a ser altamente significativa, com $\mathrm{p}=0,0003<1 / 1000$. Foi nesse mês, aliás, em que os maiores contrastes foram detectados no contexto de um teste de comparações múltiplas de médias, conforme a Tabela 7 .

4. Em Abril a posição da ZCIT permanece ao norte da linha do equador, em média, para os anos nas classes $-2=$ MS (muito seco) e $-1=\mathrm{S}$ (seco) na Bacia Metropolitana. Já para as classes $0=\mathrm{N}$ (normal), $1=\mathrm{C}$ (chuvoso) e $2=\mathrm{MC}$ (chuvoso), situa-se ao sul do equador. A Análise da Variância mantém-se altamente significativa, em vista de uma probabilidade de erro $\mathrm{p}=0,0005<1 / 1000$.

5. Em Maio, para as duas classes $-2=\mathrm{MS}$ e $-1=\mathrm{S}$, a ZCIT já migrou, no meridiano $37^{\circ} \mathrm{W}$, para uma posição média entre $2^{\circ} \mathrm{N}$ e $3^{\circ} \mathrm{N}$, isto é, bem ao norte da linha do equador. Note-se que para as classes de anos $0=\mathrm{N}$ (normal) e 1 = C (chuvoso), sua posição média também já se situa no hemisfério norte, porém entre o equador e a latitude de $1^{\circ} \mathrm{N}$. Contudo, para os anos $2=\mathrm{MC}$ (muito chuvoso), a posição média da ZCIT ainda se encontra um pouco ao sul da linha do equador. No caso, as diferenças detectadas pela Análise de Variância mostram-se ainda estatisticamente significativas, com $\mathrm{p}=0,004<1 \%$.

6. Finalmente, em Junho, quando a "quadra chuvosa" costuma já estar encerrada, note-se que por sua vez a ZCIT migrou inteiramente para o hemisfério Norte, com posições médias alcançadas entre $3,5^{\circ} \mathrm{N}$ e $5,5^{\circ} \mathrm{N}$, aproximadamente. A Análise de Variância não mostra mais diferenças estatisticamente significativas, pois $\mathrm{p}=0,277>25 \%$. Além disso, também não ocorrem quaisquer diferenças significativas no contexto de testes de comparações múltiplas entre as classes; ou seja, o "grupo" $\{-2,-1,0,1,2\}$ é suposto homogêneo. Não obstante, o gráfico sugere que a migração (retorno) para o norte do equador mostra-se mais "rápida" nos anos secos e mais "lenta" nos anos chuvosos.

\section{Relação da posição média da ZCIT, mês a mês, de janeiro a junho, com a chuva na bacia do Alto Jaguaribe}

Para a Bacia do Alto Jaguaribe, no Sudoeste do Estado do Ceará, a influência da ZCIT ainda pode ser nitidamente sentida e, para isso, bastando inspecionar a Figura 12. 

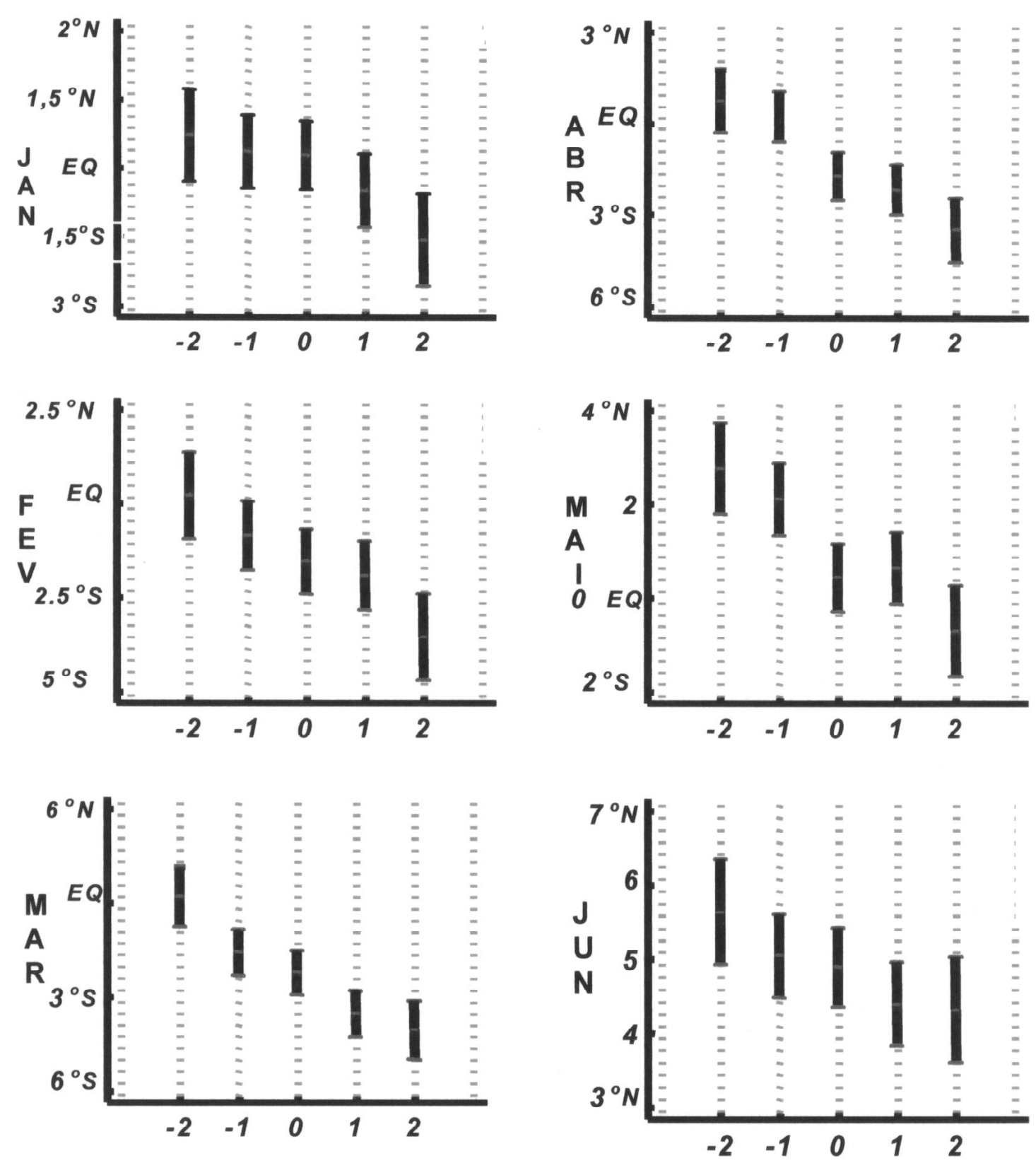

Figura 11. Bacia Metropolitana - estado do Ceará - Intervalos de Confiança para as Latitudes Médias da Posição da ZCIT ao longo do Meridiano de $37^{\circ} \mathrm{W}$, de Janeiro a Junho, relativamente às classes: $-2=\mathrm{MS}=$ Muito Seco, $-1=\mathrm{S}=\mathrm{Seco}, 0=\mathrm{N}=\mathrm{Normal}, 1=\mathrm{C}$ = Chuvoso e 2 = MC = Muito Chuvoso, durante a "quadra chuvosa" (fevereiro-maio) para a referida bacia, 1964-1998.

Note-se, neste caso, que para JANEIRO, FEVEREIRO e JUNHO, as probabilidades de erro (ou níveis de significância) nas Análises de Variância foram $\mathrm{p}=$ $0,19>20 \%, p=0,066>5 \%$ e $p \cong 0,20=20 \%$, respectivamente. Para MARÇO e ABRIL, porém, as Análises de Variância passam a dar resultados altamente significativos, com probabilidades de erro muito pequenas: $\mathrm{p}=0,0018<2 / 1000$ e $\mathrm{p}=0,0007<1 / 1000$. Finalmen- te, para o mês de MAIO, tem-se $\mathrm{p}=0,015<2 \%$, donde um resultado ainda foi significativo.

Por outro lado, entre Fevereiro e Maio, mais uma vez denota-se que as posições latitudinais médias alcançadas pela ZCIT, sobre o meridiano de $37^{\circ} \mathrm{W}$, decrescem, progressivamente desde a classe $-2=\mathrm{MS}$ (muito seco) até à classe $2=\mathrm{MC}$ (muito chuvoso). Na Tabela 8 tem-se o resultado da Análise de Variância com respeito à variável Z3704, isto 
RBRH - Revista Brasileira de Recursos Hidricos Volume 8 n.2 Abr/Jun 2003, 111-126

Tabela 5. Análise de variância para a posição latitudinal média da ZCIT no meridiano de $37^{\circ} \mathrm{W}$ em janeiro (Z3701), respeito às 5 Classes da chuva em fevereiro-maio, na Bacia Metropolitana (referentes a m0h_fm) ${ }^{1}$.

\begin{tabular}{lccccc}
\hline $\begin{array}{l}\text { Dados : Z3701 } \\
\text { Intervalos de confiança } 95 \%\end{array}$ & & \multicolumn{2}{c}{5 classes: referentes a m0h_fm } \\
$\begin{array}{l}\text { Origem da variação } \\
\text { Soma de quadrados }\end{array}$ & $\mathrm{gdl}^{*}$ & Média dos quadrados & razão-F & Nível de significância** \\
\hline Entre classes & 18,270468 & 4 & 4,5676171 & 1,879 & 0,1401 \\
Intra classes & 72,936389 & 30 & 2,4312130 & & \\
Total & 91,206857 & 34 & & & \\
\hline
\end{tabular}

Separadas pelos “quantis” Q $(0,15), \mathrm{Q}(0,35), \mathrm{Q}(0,65)$ e Q(0,85); * Graus de liberdade; ** Probabilidade de erro; 1 valor “missing” excluido.

Tabela 6. Teste de comparações múltiplas para a posição média da ZCIT no meridiano $37^{\circ} \mathrm{W}$ em janeiro (Z3701), com respeito às 5 Classes para a chuva em fevereiro-maio, na Bacia Metropolitana (referentes pois a $\left.\mathrm{m} 0 \mathrm{~h} \_\mathrm{fm}\right)^{1}$.

\begin{tabular}{cccc}
\hline Classe & $\#$ & Média & Grupos Homogêneos* \\
\hline 2 & 5 & $-1,5600000$ & $\mathrm{X}$ \\
1 & 8 & $-0,4875000$ & $\mathrm{X} \mathrm{X}$ \\
1 & 9 & 0,2888889 & $\mathrm{X}$ \\
-1 & 8 & 0,3625000 & $\mathrm{X}$ \\
-2 & 5 & 0,7200000 & $\mathrm{X}$ \\
\hline
\end{tabular}

${ }^{1}$ Separadas pelos "quantis" $\mathrm{Q}(0,15), \mathrm{Q}(0,35), \mathrm{Q}(0,65)$ e $\mathrm{Q}(0,85)$;

* Neste caso, há dois grupos, correspondentes às duas colunas nas quais se distribuem os " $\mathrm{X}$ ". Note-se que os dois grupos se interpenetram, pois a "classe 1" pertence, simultaneamente, a ambos os grupos.

é, para a posição média da ZCIT em Abril. Estão aqui omitidas as tabelas das análises de variância para os demais meses, bem como, as tabelas para os resultados dos vários testes de comparações múltiplas.

\section{Reavaliação de resultados precedentes}

Os resultados anteriores, referentes às Bacias Metropolitana e do Alto Jaguaribe, merecem ser reavaliados considerando que os números de observações ou freqüências das 5 (cinco) classes são pequenos. Por exemplo, para a Bacia Metropolitana, as freqüências são 5, 8, 11, 8 e 9, respectivamente; para a Bacia do Alto Jaguaribe, 5, 7, 11, 7 e 5, respectivamente. A simetria com respeito às freqüências das classes decorre, por sua vez, da simetria na escolha das "ordens quantílicas" utilizadas para definir os extremos dos intervalos de classes. Embora, "a priori", não se pudesse garantir uma simetria perfeita com relação às freqüências observadas em vista de flutuações da amostragem.

De fato, como as freqüências das classes são pequenas, seria de esperar a existência de algum viés na determinação dos intervalos de confiança para os valores médios da ZCIT. Não obstante, isso pode ser controlado mediante a inspeção de gráficos nos quais comparecem os valores observacionais das posições latitudinais da ZCIT respeito às várias classes, em vez dos respectivos intervalos de confiança, estimados. Por exem-
Tabela 7. Teste de comparações múltiplas para a posição média da ZCIT no meridiano $37^{\circ} \mathrm{W}$ em março (Z3703), com respeito às 5 Classes para a chuva em fevereiro-maio, na Bacia Metropolitana (referentes pois a $\left.\mathrm{m} 0 \mathrm{~h} \_\mathrm{fm}\right)^{1}$.

\begin{tabular}{cccc}
\hline Classe & $\#$ & Média & Grupos Homogêneos* \\
\hline 2 & 5 & $-4,0400000$ & $\mathrm{X}$ \\
1 & 8 & $-3,5250000$ & $\mathrm{X} \mathrm{X}$ \\
0 & 9 & $-2,2111111$ & $\mathrm{X} X$ \\
-1 & 8 & $-1,5750000$ & $\mathrm{X}$ \\
-2 & 5 & 0,2000000 & $\mathrm{X}$ \\
\hline
\end{tabular}

${ }^{1}$ Separadas pelos "quantis" Q $(0,15), \mathrm{Q}(0,35), \mathrm{Q}(0,65)$ e $\mathrm{Q}(0,85)$;

* Note-se, agora, haver "4 grupos", que também se interpenetram, exceto o grupo unitário $\{-2\}$.

plo, para os valores da ZCIT no mês de Abril, referentes às classes na Bacia Metropolitana, dispõe-se da Figura 13.

De fato, comparando este gráfico (Figura 13) com aquele que corresponde aos intervalos de confiança das posições médias da ZCIT, também em Abril (Figura 11), chega-se à conclusão de serem compatíveis entre si, a menos de um "outlier" (valor excessivamente elevado indicado por uma seta) para uma das posições latitudinais da ZCIT, na classe $0=\mathrm{N}$ (normal).

Outra modalidade de controle consiste na realização do teste de Kruskal-Wallis (que se considera como uma "análise de variância não-paramétrica”) com respeito às variáveis Z3701, ...., Z3706, levando em conta as cinco classes $-2=\mathrm{MS},-1=\mathrm{S}$, $0=\mathrm{N}, 1=\mathrm{C}$ e $2=\mathrm{MC}$, tanto para os dados de chuva na Bacia Metropolitana, como na Bacia do Alto Jaguaribe. Para o caso da Bacia Metropolitana, os níveis de significância obtidos foram, respectivamente, $\mathrm{p}=0,077<10 \% ; \mathrm{p}=0,0199 \cong 2 \% ; \mathrm{p}=$ $0,00157<2 / 1000 ; \mathrm{p}=0,00095 \cong 1 / 1000 ; \mathrm{p}=0,0231<2,5 \%$; $\mathrm{p}=0,237>20 \%$. Quanto à Bacia do Alto Jaguaribe, obtidos: $\mathrm{p}=0,232>20 \% ; \mathrm{p}=0,0559>5 \% ; \mathrm{p}=0,008<1 \%$; $\mathrm{p}=0,0034<5 / 1000 ; \mathrm{p}=0,0766>5 \% ; \mathrm{p}=0,208 \cong 20 \%$.

\section{A ZCIT e a chuva nas demais bacias}

Com respeito às demais bacias (dos rios Acaraú, Coreaú, Banabuiú e Salgado) os resultados são análogos. Para algumas dessas bacias trabalhou-se apenas com 3 
Tabela 8. Análise de variância para a posição latitudinal média da ZCIT no meridiano de $37^{\circ} \mathrm{W}$ em abril (Z3704), respeito às 5 Classes da chuva em fevereiro-maio, na Bacia do Alto Jaguaribe (referentes a j1h_fm) ${ }^{1}$.

\begin{tabular}{lccccc}
\hline $\begin{array}{l}\text { Dados : Z3701 } \\
\text { Intervalos de confiança 95\% }\end{array}$ & & \multicolumn{2}{c}{ 5 classes: referentes a j1h_fm } \\
Origem da variação & Soma de quadrados & gdl* $^{*}$ & Média dos quadrados & razão-F & Nível de significância** \\
\hline Entre classes & 69,261251 & 4 & 17,315338 & 6,854 & 0,0007 \\
Intra classes & 80,165506 & 30 & 2,672184 & & \\
Total & 149,42686 & 34 & & & \\
\hline
\end{tabular}

${ }^{1}$ Separadas pelos “quantis” Q(0,15), Q(0,35), Q(0,65) e Q(0,85); * Graus de liberdade; ** Probabilidade de erro.

(três) classes: $-1=\mathrm{MS}$ ou $\mathrm{S} ; 0=\mathrm{N} ; 1=\mathrm{C}$ ou MC; com efeito, para fins da análise de variância, teríamos freqüências excessivamente pequenas em algumas das cinco classes originais.

\section{CONSIDERAÇÕES FINAIS}

Os resultados obtidos neste artigo confirmam a importância da migração da ZCIT (Zona de Convergência Intertropical) a latitudes ao sul da linha do equador, sobre o Atlântico intertropical sul e a área continental, em termos de constituir o principal sistema atmosférico responsável pelo desencadeamento de chuvas sobre o Estado do Ceará e, particularmente, sobre as suas bacias hidrográficas. Por outro lado, também mostram inequivocamente o papel de eventos ENOS - "El Niño-Oscilação Sul". Lembremos, ademais, que a movimentação da ZCIT - Zona de Convergência Intertropical está ligada a outros fenômenos meteorológico-oceanográficos, em particular a formação do "dipolo" no Atlântico intertropical, conforme Moura e Shukla (1981) bem como, o enfraquecimento da componente meridional do vento junto à costa do Nordeste brasileiro a que já se fez menção. Na verdade essa é uma questão complexa cuja discussão está fora do contexto do presente trabalho.

A Região do Cariri, no quadrante sudeste do Ceará, costuma-se considerar em separado, pois sua "quadra chuvosa" coincide, geralmente, com o quadrimestre janeiro-abril. Além disso, incursões das "frentes frias do sul" parecem ali exercer um papel significativo com respeito à ocorrência de certos episódios de chuvas; em alguns casos, podendo mesmo originar chuvas em outras áreas do Estado do Ceará. Daí a importância que teria numa etapa ulterior deste trabalho que pudesse ser empreendida uma análise detalhada para a chuva na Bacia do Rio Salgado, por exemplo, não só com relação à posição da ZCIT como, também, com respeito às incursões das frentes frias.

Por outro lado, seria válido também examinar a questão da recarga das reservas hídricas do Estado do Ceará, em especial no que concerne aos grandes açudes situados nas suas diversas bacias hidrográficas, em função igualmente de eventos ENOS e das incursões da ZCIT ao sul da linha do equador.

De fato, esta modalidade de trabalho fornece subsídios para a análise da vulnerabilidade climática dessas bacias hidrográficas. Por outro lado, relaciona-se intimamente com o Projeto "Tempo de Chuva" para previsão regionalizada da chuva no Estado do Ceará e nas suas bacias durante a "quadra chuvosa", conforme Xavier et al. (1998, 2000d, 2000e); também, Xavier (2001). Podendo, igualmente contribuir com informações para o aprimoramento de outros modelos de previsão.

Uma conclusão importante, aliás, diz respeito à circunstância que a ZCIT exerce uma influência determinante não só com respeito à chuva nas áreas costeiras (como é o caso da Bacia Metropolitana) mas, também, nas áreas interioranas e no sul do Ceará (caso da Bacia do Alto Jaguaribe). Quanto à escolha do período fevereiromaio de cada ano como a "quadra chuvosa" no Ceará, fundamenta-se no fato de tratar-se do quadrimestre mais chuvoso, climatologicamente; exceção feita para o Cariri, região para a qual o quadrimestre mais chuvoso é usualmente janeiro-abril. Contudo, a análise para a posição da zona de convergência intertropical, feita mês a mês, ou seja de janeiro até junho, privilegia separadamente tanto os meses da estação chuvosa propriamente dita, como ainda um mês da "pré-estação chuvosa" (janeiro) e outro da "pós-estação" (junho).

Finalmente, acerca da utilização de técnicas estatísticas, como é o caso aqui com a análise de variância, decorrem diversas vantagens. Com efeito, por uma parte constituem, geralmente, procedimentos relativamente simples do ponto de vista conceitual, permitindo conduzir a resultados e interpretações simples e inteligíveis que, de outra forma seria difícil de obter, em especial quando ficam em jogo grandes massas de dados numéricos. Mais outro proveito é que se pode associar a cada resultado a probabilidade de erro respectiva, a qual diz respeito à possibilidade desse resultado não ser válido, no sentido de atribuível ao simples acaso. Dessa maneira, trata-se de um instrumento que permite descartar aqueles resultados menos confiáveis. No presente artigo as probabilidades de erro foram pequenas e, em certos casos, próximas 

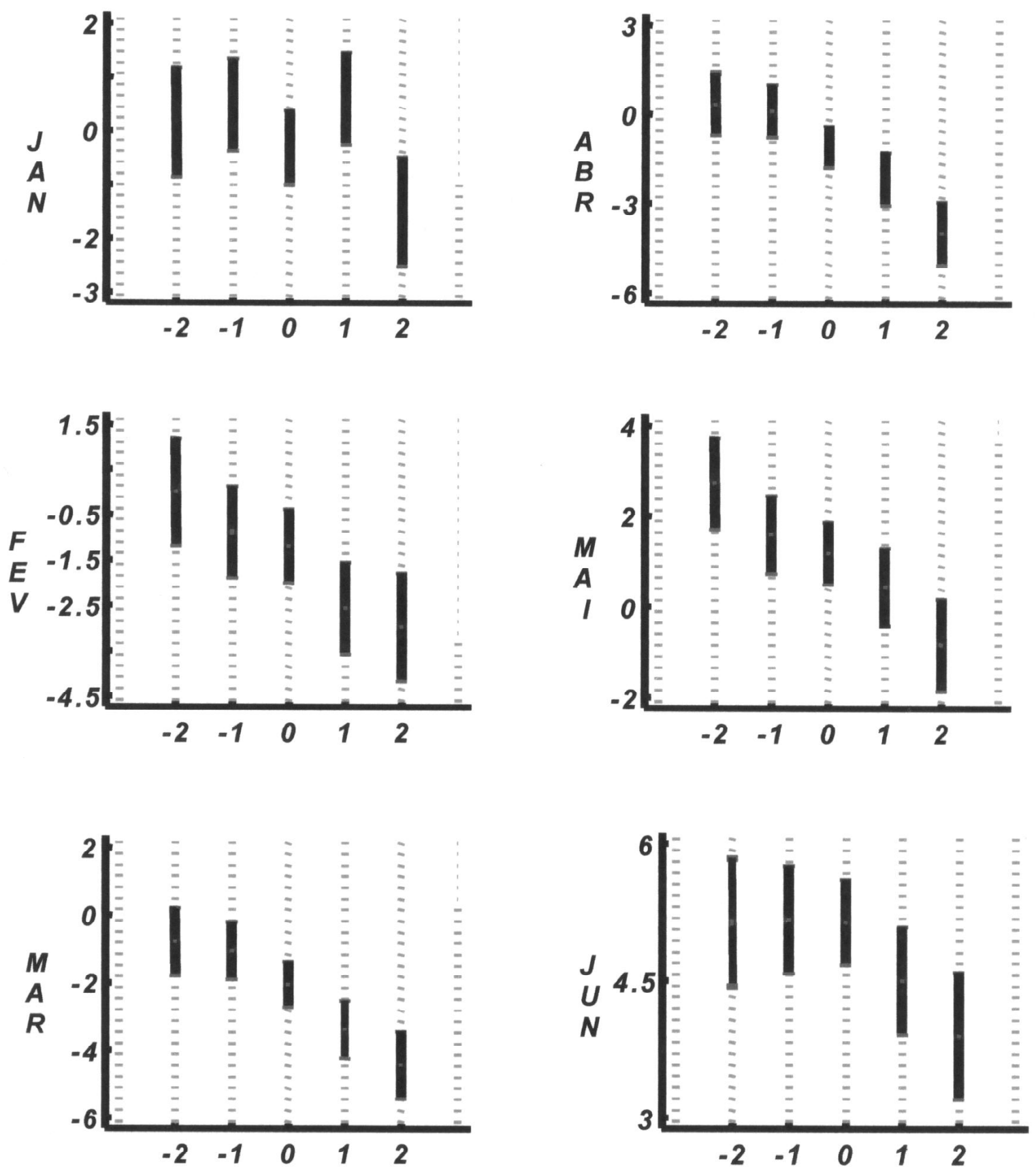

Figura 12. Bacia do Alto Jaguaribe - Estado do Ceará - Intervalos de Confiança para as Latitudes Médias da Posição da ZCIT ao longo do Meridiano de $37^{\circ} \mathrm{W}$, de Janeiro a Junho, relativamente às "classes": $-2=\mathrm{MS}=$ Muito Seco, $-1=\mathrm{S}=\mathrm{Seco}$, $0=\mathbf{N}=$ Normal, $1=\mathrm{C}=$ Chuvoso e $2=\mathrm{MC}=$ Muito Chuvoso, durante a "quadra chuvosa" (fevereiro-maio) para a referida bacia, 1964-1998.

de zero. Note-se, a respeito de métodos numéricos, que neles não há um mecanismo capaz de estimar intrinsecamente probabilidades de erro, a menos que possam vir a ser obtidas por técnicas experimentais de simulação ou técnicas de Monte Carlo.

\section{AGRADECIMENTOS}

Ao Prof. Dr. Jacques Servain, do IRD (antiga ORSTOM) - Centro da Bretanha - França, não só pela cessão dos dados da "pseudotensão" do vento no Atlântico. 


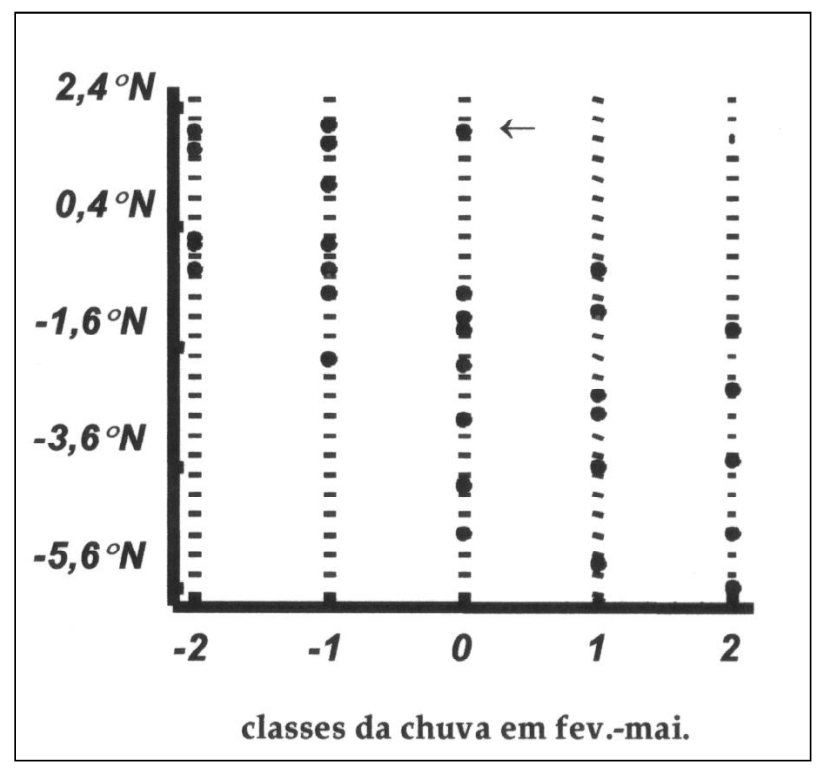

Figura 13. Pontos observacionais (bolinhas) referentes às posições latitudinais da ZCIT sobre o meridiano de $37^{\circ} \mathrm{W}$, para o mês de abril e as cinco classes $-2=\mathrm{MS},-1=\mathrm{S}, 0=$ $\mathrm{N}, 1=\mathrm{C}$ e 2 = MC da chuva observada durante a "quadra chuvosa" (fevereiro-maio) na Bacia Metropolitana.

Ao $\mathrm{CNPq}$ pelo apoio através de bolsas de pesquisa e financiamento de vários projetos, desde a década de 80; como, também, à FAPESP. Ainda à FUNCAP - Fundação Cearense de Amparo à Pesquisa pelo suporte, nos últimos anos, no que concerne à realização de pesquisas sobre a climatologia e a previsão regional da chuva no Estado do Ceará. Os agradecimentos são estendidos aos dois "revisores" cujos pareceres e sugestões contribuíram para o aprimoramento deste artigo, na sua versão final.

\section{REFERÊNCIAS}

ACEITUNO, P. (1992). El Niño, the Southern Oscillation, and ENSO: confusing names for a complex ocean-atmosphere interaction. Bulletin American Meteorological Soc, vol. 73: 483-485.

BELLEC, B.; CAMMAS, J. P.; GUILLOT, B.; LAHUEC, J. P. \& NOYALET, A. (1984). Projet de Surveillance des Amas Convectives et des Précipitations dans la Zone Intertropicale, à l'aide des données infra-rouge de Météosat. Bull. Veille Climatique Satéllitaire, n. 3, p. 19-22, CMS/ORSTOM, Lannion Éd.

BRASIL, THOMAZ POMPEU DE S. (1877). Memória sobre o clima e as secas do Ceará, Tipografia Nacional, Rio de Janeiro. Em: Vingt-un Rosado, Ed. (1983), Nono Livro das Secas, Col. Mossoroense, vol. CCLXXXV, p. 7-78.

CAVIEDES, C. N. (1973). Sêcas and El Niño: two simultaneous climatic harzards in South America. Proc. Assoc. American Geograph., vol. 5: 55-49.

CHATFIELD, C. (1970). Statistics for Technology, Penguin Books, Studies in Applied Statistics, 360 p. (3d edition, 1983).
CITEAU, J.; CAMMAS, J. P.; GOURIOU, Y. \& GUILLOT, B. (1985). Questions about the ITCZ migration over the tropical atlantic, sea surface temperature in the Gulf of Guinea and the flow of Senegal River, CCCO Meeting, Rio de Janeiro, sept 9-13, 15 p.

CITEAU, J.; BERGÈS, J. C.; DEMARCH, H. \& MAHÉ, G. (1988). The watch of ITCZ migration over tropical Atlantic as an indicator in drought forecast over Saheliann area. OceanAtmosphere Newsletter, sv(45): 1-3.

CONOVER, W. J. (1971). Practical nonparametric statistics. Wiley International Edition, 452 p. (3d edition, 1999).

COVEY, D. L. \& HASTENRATH, S. (1978). The Pacific El Niño Phenomenon and the Atlantic Circulation. Monthly Weather Rev., vol. 106: 1280-1287.

DORIZE, L. (1989). La position du front inter-tropical en Afrique occidentale sahélienne et les causes probables de sa mobilité. Em: Bret, B., Coord., les Hommes Face AUX Secheresses Nordeste Brésilien et Sahel African, IHEAL \& EST Ed., Collection IHEAL, n. 42/Série Thèses et Colloques n. 1, Institut des Hautes Etudes de l'Amérique Latine, Université de Paris III/Nouvelle Sorbonne, Paris, 423 p., p. 53-62.

ENFIELD, D. B. (1989). El Niño, Past and Present, Reviews on Geophysics, vol. 27: 159-187.

ESSENWANGER, O. M. (1986). Elements of statistical analysis, general climatology 1-B, Elselvier Science Publishers, Amsterdam, $424 \mathrm{p}$.

ESTADO DO CEARÁ/SRH-SOHIDRA-FUNCEME (1992). Plano Estadual dos Recursos Hídricos, Estudos de Base I, Fortaleza-Ceará, p. I-XXVII/407-867.

FLOHN, H. (1960). Intertropical Convergence Zone and Meteorological Equator, W. M. O., Tech. Note n. 64, Geneva, p. 21-29.

FRANK, W. M. (1983). The structure and energetic of the east Atlantic intertropical convergence zone.J. of Atmosph. Sciences, vol. 40: 1916-1929.

GRUBER, A. (1972). Fluctuations in the position of ITCZ in the Atlantic and Pacific Oceans. J. of Atmosph. Sciences, vol. 29: 193-197.

GUENTHER, W. C. (1965). Concepts of Statistical Inference, McGraw-Hill Book Co., New York - Kogakusha Co. Ltd., Tokyo, International Student Edition, 354 p. (2 $2^{\text {nd }}$ edition, 1973).

HASTENRATH, S. \& HELLER, L. (1977). Dynamics of climatic harzards in northeast Brazil. Quart. J. Royal Meteorological Soc., vol. 103: 77-92.

HUMBOLDT, A. VON (1843-1858). Kosmos (volumes sucessivos publicados nesse período; existe uma tradução para o espanhol pela editora Espasa-Calpe, Madrid, 1949, com material referente a Geomagnetismo, Oceanos e Atmosfera).

ILUSANMI, O. O. (1971). An Empirical Formulation of an ITD Rainfall Model for the Tropics: A Case Study of Nigeria. J. Applied Meteorology, vol. 10: 882-891.

MACEDO, M. V. A. (1981). Aproveitamento hídrico das bacias fluviais do Ceará. Ministério do Interior, DNOCS, Fortaleza, CE, 176 p.

MARENGO, J. A. (1995). Interannual variability of deep convection over the tropical South American sector as 
deduced from ISCCP C2 Data. International J. of Climatology, vol. 15: 995-1010.

MARENGO, J. A.; DRUYAN, L. M. \& HASTENRATH, S. (1993). Observational and modeling studies of Amazonia interannual climate variability. Climatic Change, vol. 23: 267-286.

MARKHAM, C. G. \& McLAIN, D. R. (1977). Sea surface temperature related to rain in Ceará, North-Eastern Brazil. Nature, vol. 265: 320-323.

MAURY, M. F. (1855). The physical geography of the sea. Harper \& Brothers Publishers, New York, 275 p.

McQUATE, G. T. \& HAYDEN, B. P. (1984). Determination of intertropical convergence zone rainfall in northeastern Brazil using infrared satellite imagery. Arch. Met. Geophys. Biocl., Series B, vol. 34: 319-328.

MELLO, A. B. C. de; NOBRE, P.; MELO, M. L. D. de \& SANTANA, S. C. (2000). Estudo climatológico da posição da ZCIT no Atlântico Intertropical e sua influência sobre o nordeste do Brasil. Anais do XI CBMET-Congresso Brasileiro de Meteorologia (em CD-ROM, 5 p.), Rio de Janeiro, 16-20 de Outubro.

MOURA, A. D. \& SHUKLA, J. (1981). On the dynamics of droughts in North-East Brazil: observations, theory, and numerical experiments with a general circulation model. $J$. of Atmosph. Sciences, vol. 38: 2653-2675.

NOBRE, P. (1993). On the genesis of anomalous SST and rainfall patterns over the tropical Atlantic basin. Ph.D. Thesis, Department of Meteorology, University of Maryland at College Park, $151 \mathrm{p}$.

PICAU, J.; SERVAIN, J. et al. (1985). Climatic Atlas of the Tropical Atlantic Wind Stress and Sea Surface Temperature 1964-1979, Université de Bretagne Occidentale-University of Hawaii, 467 p.

PINKAYAN, S. (1966). Conditional Probabilities of Occurrence of Wet and Dry Years Over a Large Continental Area; Hydrology Papers, Number 12, Colorado State University, FortCollins, Colorado-USA, $53 \mathrm{p}$.

QUINN, H. W. \& ZOPF, D. O. (1975). The Southern Oscillation, Equatorial Pacific Anomalies and El Niño. Geofisica Internacional, vol. 15, n. 4: 327-353.

QUINN, H. W.; NEAL, V. \& MAYOLO, S. E. A. (1987). El Niño Occurrences over the Past Four and a Half Centuries. J. of Geophysical Res., 92, n. C13, 14.449-14.461.

SACHS, L. (1978). Estatística aplicada. Editorial Labor S.A., Barcelona, trad. de G. W. Keurleber (original em alemão, Springer-Verlag, Berlin-Heildelberg) 568 p.

SERRA, A. \& RATISBONA, L. (1942). As massas de ar da América do Sul. Serviço de Meteorologia, Ministério da Agricultura, 137 p.

SERVAIN, J. (1985). Variations Interannuelles en Atlantique. Thèse presentée à l'Université de Bretagne Occidentale pour obtenir le grade de Docteur ès Sciences Physiques, 200 p.

SERVAIN, J. \& PICAUT, J. et al (1984). A 16 year Series of Observations of Sea Surface Temperature and Wind Stress Field in the Tropical Atlantic. Intergovernmental Oceanographic Commission - Tech. Series: Time Series of Ocean Measurements, vol. 2, UNESCO.

SERVAIN, J. \& PICAUT, J. et al (1985). Interannual and Seasonal Variability in the Tropical Atlantic Ocean Depicted by Sixteen
Years of Sea-Surface Temperature and Wind Stress. Em: J. C. J., Editor, Coupled Ocean-Atmosphere Models, Chapter 16, p. 211-237. Elsevier Publ., Amsterdam.

SERVAIN, J. \& SEVA, M. (1987). On Relationships between Tropical Atlantic Sea Surface, Wind Stress and Regional Precipitations Indices, Ocean-Air Interactions, vol. 1: 183-190.

UVO, C. B. (1989). Dissertação de Mestrado: A Zona de Convergência Intertropical (ZCIT) e sua Relação com a Precipitação no Nordeste Brasileiro, INPE, São José dos Campos.

WALKER, G. T. (1928). Ceará (Brazil) Famines and the General Air Movement. Beitr. Phys. Atmos. vol. 14: 88-93.

XAVIER, T. de Ma. B. S. \& XAVIER, A. F. S. (1984a). Dry and Wet Periods Characterization Over Drougth Polygon (Polígono das Secas) in Northeast Brazil, 2nd. WMO Symposium on Meteorological Aspects of Tropical Droughts, Fortaleza-Ceará (versão estendida: Relatório de Pesquisa, 52 p., Fortaleza, CE).

XAVIER, T. de Ma. B. S. \& XAVIER, A. F. S. (1984b). Classificação de Anos Secos e Chuvosos na Região NE. do Brasil e sua Distribuição Espacial. Anais do III Congresso Brasileiro de Meteorologia, Belo Horizonte, vol. 3, p. 267-275.

XAVIER, T. de Ma. B. S. \& XAVIER, A. F. S. (1987a). Aplicação de Filtragem Binária no Estudo da Ocorrência de Períodos Secos ou Chuvosos no Nordeste Brasileiro. Anais do $7^{\circ}$ Simpósio Brasileiro de Hidrologia e Recursos Hídricos $/ 3^{\circ}$ Simpósio Luso-Brasileiro de Hidráulica e Recursos Hídricos, Salvador-Bahia, Novembro, vol. 2, p. 617-629.

XAVIER, T. de Ma. B. S. \& XAVIER, A. F. S. (1987b). Classificação e Monitoração de Períodos Secos ou Chuvosos e Cálculo de Índices Pluviométricos para a Região Nordeste do Brasil. Revista Brasileira de Engenharia. Caderno de Recursos Hídricos, vol. 5, n. 2: 7-31.

XAVIER, T. de Ma. B. S. \& XAVIER, A. F. S. (1989). Caractérisation et Moniteurisation des Periodes Sèches et Pluvieuses au Nord-Est du Brésil. Em: Bret, B., Coord., Les Hommes Face AUX Secheresses - Nordeste Brésilien et Sahel African, IHEAL \& EST Ed., Collection IHEAL, n. 42/Série Thèses et Colloques n. 1, Institut des Hautes Etudes de l'Amérique Latine, Université de Paris III/Nouvelle Sorbonne, Paris, 423 p., p. 93-99.

XAVIER, T. de Ma. B. S \& XAVIER, A. F. S. (1990). Binary Filtering for the Study of Persistence and Alternance of Dry and Wet Years in Northeast-Brazil. Extended Abstracts of Papers Presented at the $3^{d}$ WMO Symposium on Meteorological Aspects of Tropical Droughts With Emphasis on Long-Range Forecasting; NiameyNiger (Tropical Meteorology Research Programme Report Series), Report n. 36/WMO/TD-N. 353, p. 255-261.

XAVIER, T. de Ma. B. S.; SILVA DIAS, Ma. A. F. da \& XAVIER, A. F. S. (1994). Evolução da Precipitação Diária num Ambiente Urbano: O Caso da Cidade de São Paulo. Rev. Bras. de Meteorologia, vol. 9, n. 1: 44-53.

XAVIER, T. de Ma. B. S.; SILVA DIAS, M. A. F. da \& XAVIER, A. F. S. (1995). Impact of ENSO Episodes on the Autumn Rainfall Patterns Near São Paulo. International Journal of Climatology, vol. 15, n. 5: 571-584. 
XAVIER, T. de Ma. B. S. \& XAVIER, A. F. S. (1996). Alterações Climáticas Urbanas em Fortalez̧a, Ceará (1974-95). CBMET/ 96-Congresso Brasileiro de Meteorologia.

XAVIER, A. F. S.; XAVIER, T. de Ma. B. S. \& SILVA DIAS, P. L. (1996). Temperature Changes at São Paulo-Brazil, Vol. Abstracts. Conference on Environmetrics on Brazil (7th International Conference of Quantitative Methods on Environmental Sciences, Institute of Mathematics and Statistics - University of São Paulo, SP-Brazil, July 22-26, 3 p.

XAVIER, T. de Ma. B. S. \& XAVIER, A. F. S. (1997). Papel da Componente Meridional do Vento na Costa do Nordeste para a Previsão da Chuva no Estado do Ceará. Em: Artigos Selecionados do XII Simpósio Brasileiro de Recursos Hídricos, 16-20 Nov./97, Vitória-ES, Anais, vol. 1, p. 537-543.

XAVIER, T. de Ma. B. S.; XAVIER, A. F. S.; SILVA DIAS, P. L. da \& SILVA DIAS, M. A. F. da (1997-1998). Papel da Componente Meridional do Vento na Costa do Nordeste Brasileiro e de Outras Covariáveis para Prever a Chuva no Estado do Ceará (1964-1997): Cadernos Atena,n. 7A, 1997, Fortaleza, Ceará, 23 p. (pre-print) e Revista Brasileira de Recursos Hídricos, 1998, vol. 3, n. 4: 121-139.

XAVIER, T. de Ma. B. S.; XAVIER, A. F. S.; SILVA DIAS, P. L. da \& SILVA DIAS, M. A. F. da (1998). Componente Meridional do Vento na Costa do Nordeste e a ZCIT: Relações com a Chuva (1964-98). Anais do X Congresso Brasileiro de Meteorologia e VIII Congresso da FLISMET (em CD-ROM, 5 p.), Brasília, Outubro 1998; reproduzido em Cadernos Atenas, n. 13, Novembro 1998, Fortaleza, Ceará.

XAVIER, T. de Ma. B. S. \& XAVIER, A. F. S. (1998). Quantis para Séries Pluviométricas do Estado do Ceará e Caracterização de Períodos Secos ou Excepcionalmente Chuvosos. Anais do X Congresso Brasileiro de Meteorologia e VIII Congresso da FLISMET (em CD-ROM, 5 p.), Brasília, Outubro 1998.

XAVIER, T. de Ma. B. S. \& XAVIER, A. F. S. (1999). Caracterização de Períodos Secos ou Excepcionalmente Chuvosos no Estado do Ceará através da Técnica dos Quantis: 1964-1998. Revista Brasileira de Meteorologia, vol. 14, n. 2: 63-78.

XAVIER, A. F. S.; XAVIER, T. de Ma. B. S. \& MALVEIRA, H. (1999). A Zona de Convergência Intertropical-ZCIT e suas Relações com a Chuva das Principais Bacias Hidrográficas do Ceará, Anais do Simpósio Brasileiro de Recursos HídricosABRH, Belo Horizonte-MG (em CD-ROM, 16 p.).

XAVIER, T. de Ma. B. S.; SILVA, J. de F. da \& REBELLO, E. R. G. (2002a). A Técnica dos Quantis e suas Aplicações em Meteorologia, Climatologia e Hidrologia, com ênfase para as Regiões brasileiras, Thesaurus Editora de Brasília Ltda., 140 p.

XAVIER, T. de Ma. B. S. (2002b). A Técnica dos Quantis e suas Aplicações em Meteorologia, Climatologia e Hidrologia, texto de Mini-Curso no XII-CBMET/III Seminário Bras. de Climatologia, $43 \mathrm{p}$.

XAVIER, T. de Ma. B. S.; XAVIER, A. F. S.; SILVA DIAS, P. L. da \& SILVA DIAS, M. A. F. da (2000a). A Zona de Convergência Intertropical-ZCIT e suas Relações com a Chuva no Ceará (1964-98). Revista Brasileira de Meteorologia/Brazilian J. Meteorology, vol. 15, n. 1: 27-43.
XAVIER, A. F. S.; XAVIER, T. de Ma. B. S. \& ALVES, J. M. B. (2000b). Uma Análise da Cronologia de Eventos ENOS (El Niño e La Niña): 1900-2000. Anais do XI CBMET Congresso Bras. de Meteorologia (em CD-ROM, 10 p.), Rio de Janeiro, 16-20 de Outubro.

XAVIER, T. de Ma. B. S.; XAVIER, A. F. S.; ALVES, J. M. B. \& OUTROS (2000c). Climatologia da Precipitação no Ceará e suas Relações com Eventos El Niño e La Niña: 1900-1999. Anais do XI CBMET - Congresso Brasileiro de Meteorologia (em CD-ROM), Rio de Janeiro, 16-20 de Outubro.

XAVIER, T. de Ma. B. S.; XAVIER, A. F. S.; SILVA DIAS, P. L. da \& SILVA DIAS, M. A. F. da (2000d). Previsão Regional da Chuva para o Estado do Ceará através do Projeto Tempo de Chuva: 1964-1999. Revista Brasileira de Recursos Hídricos, vol. 5, n. 3: 69-92.

XAVIER, T. de Ma. B. S.; XAVIER, A. F. S.; SILVA DIAS, P. L. da \& SILVA DIAS, M. A. F. da (2000e). Modelos Estocásticos de Previsão Regional da Chuva no Ceará: Avaliação para as Quadras Chuvosas de 1997 a 2000. Anais do XI CBMETCongresso Brasileiro de Meteorologia (em CD-ROM) Rio de Janeiro, 16-20 de Outubro.

XAVIER, T. de Ma. B. S. (2001). Tempo de Chuva: Estudos Climáticos e de Previsão para o Ceará e Nordeste Setentrional. ABC Editora, Fortaleza-Ceará, 478 p.

\section{Interrelations Between ENSO Events, ITCZ in the Atlantic and Rainfall in the River Basins of Ceará}

\section{ABSTRACT}

An evaluation is presented of the interrelations between ENSO ("ElNiño-Southern Oscillation") episodes in the Pacific and the mean monthly positions of the ITCZ ("Intertropical Convergence Zone") in the Atlantic, as well as the rainfall over the river basins in the State of Ceara-Brazil during the "rainy season" or the four-month period from February to May. Actually, only 6 (six) of the 11 (eleven) basins usually considered for the State of Ceara are treated. However, they cover a significant fraction of its total surface and the most important areas of the state, both as to population and economically. The results reveal a significant role for ITCZ migration to the south of the Equator, closer to the territory of Ceará-Northeast Brazil, as regards the occurrence of regular rains over their river basins, not only for those located close to the coast but also those situated in the backlands or in the south of the state. The significance of the ENSO episodes with respect both to the position of the ITCZ south of the Equator and the rainfall over the Ceará basins has also been demonstrated. The results provide a basis for the studies on the climatic vulnerability of these river basins.

Key words: ITCZ in the Atlantic; ENSO episodes; rainfall in the Ceará river basins. 